\title{
THE ROLE OF THE EDUCATIONAL SUPERVISOR IN DEVELOPING TEACHERS' FUNCTIONAL PERFORMANCE AT THE POST-BASIC EDUCATION SCHOOLS IN MUSCAT GOVERNORATE: TEACHERS' PERSPECTIVES
}

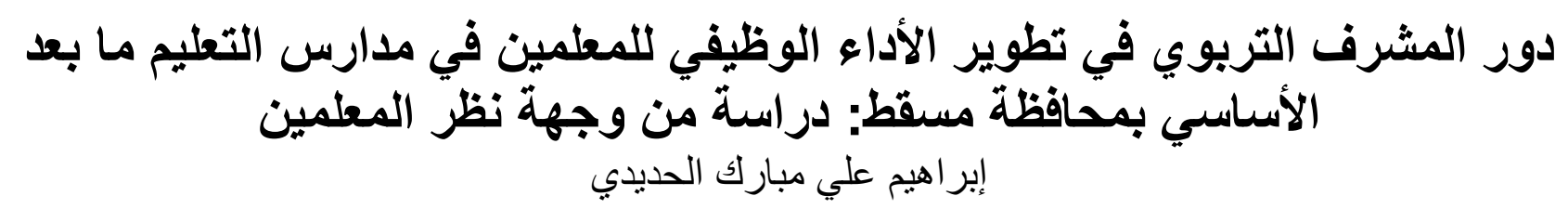

Ibrahim Ali Mubarak Alhadidi ${ }^{1 *} \&$ Dawood Abdulmalek yahya Al-Hidabi ${ }^{2}$

${ }^{1}$ Ph.D. Candidate at the Faculty of Education (IIUM); ebrheem99@moe.om

${ }^{2}$ Prof. Dr. at the Faculty of Education (IIUM); dawood@iium.edu.my

${ }^{*}$ Corresponding Author

\begin{abstract}
This quantitative study discusses the role of the educational supervisor in developing teachers' performance at the in the post-primary education schools in Muscat Governorate, through revealing the supervisory practices of the educational supervisors, as well as detecting the differences in the study sample responses according to (gender and experience) variables. To achieve these objectives; the researcher used descriptive analytical method, and designed a questionnaire consisting of (30) paragraphs divided into five areas: (human relations, planning, training and professional growth, field monitoring, assessment and tests). The study population consists of (1440) teachers of post-primary schools in the Governorate of Muscat. The random sample consists of (341) male and female teachers. After the data descriptive analysis through the statistical processing of the SPSS program, the findings revealed that: the role of the educational supervisor in the development of the teachers' performance in the area of (human relations) was big, while the supervisors' practices in areas of (Planning, training and professional growth, field follow-up, evaluation and testing) were at medium levels according to the teachers' point of view. There were statistically significant differences at the mean level $(\alpha \leq 0.05)$ according to the gender variable in favor of the male teachers. There were no statistically significant differences for the experience variable.
\end{abstract}

Keywords: Educational Supervisor, Performance Development, Post-Basic Education.

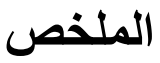

هدفت هذه الدراسة الكمية إلى تشخيص دور المشرف التربوي في تطوير الأداء الوظيفي

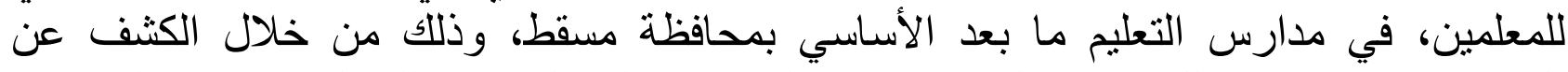
الممارسات الإشر افية للمشرفين التربوبين في المجالات المختلفة، وكذلك الكثف عن الفروقات 


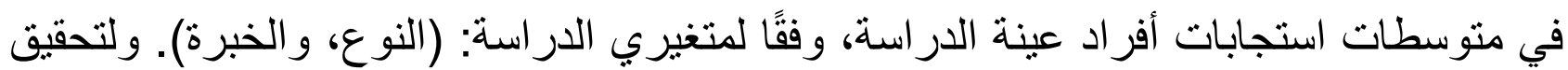

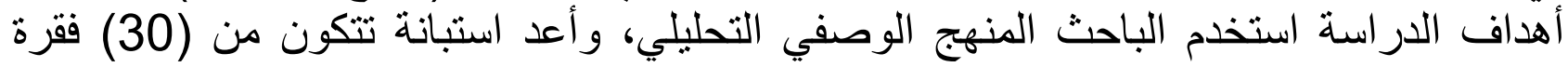

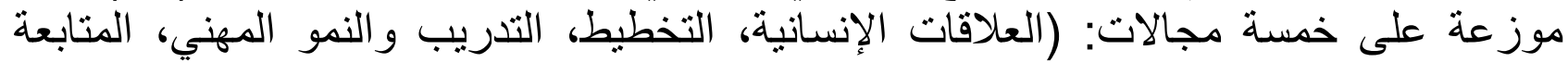

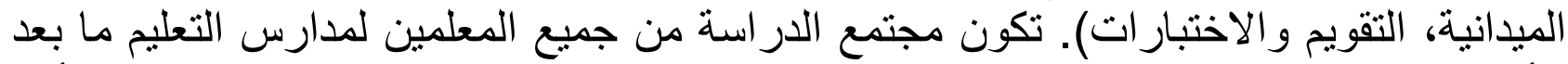

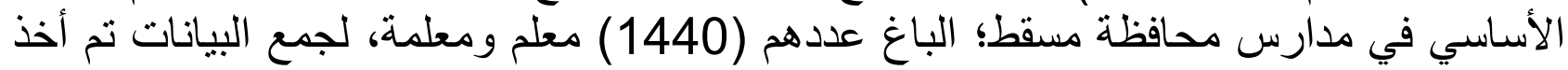

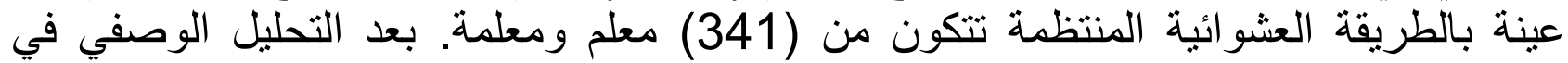

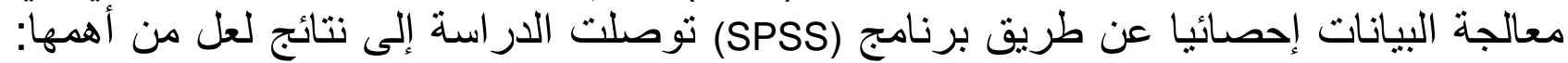

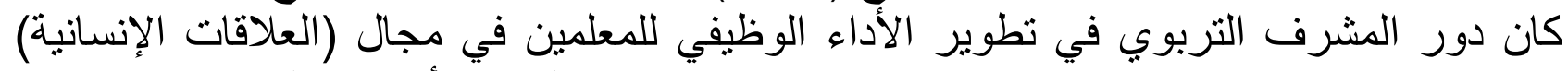

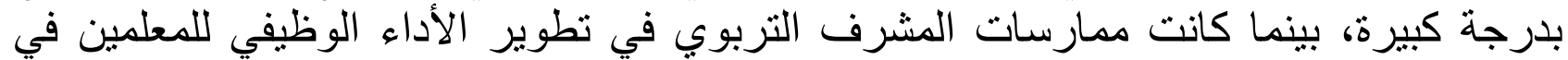

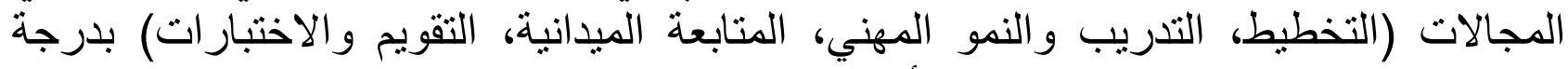

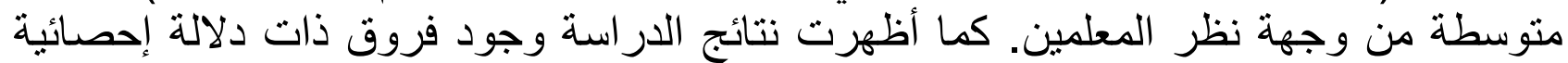

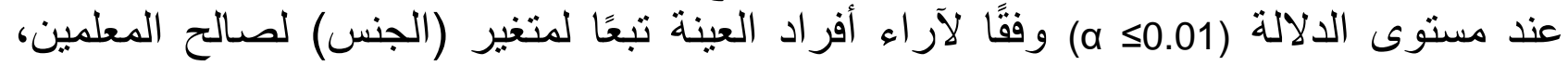

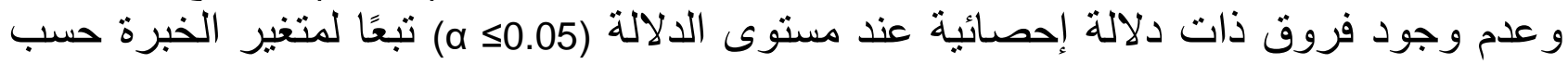

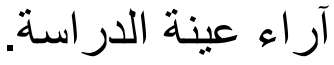

الكلمات المفتاحية: المشرف التربوي، تطوير الأداء، التعليم ما بعد الأساسي.

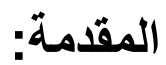

تعثبر التربية الأداة الأولي والأمثل في تمثيل المجتمعات لنقل نراثه وحفظه، وكذللك الوسيلة

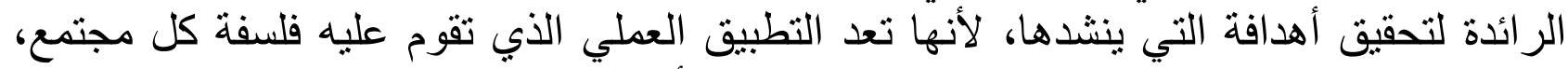

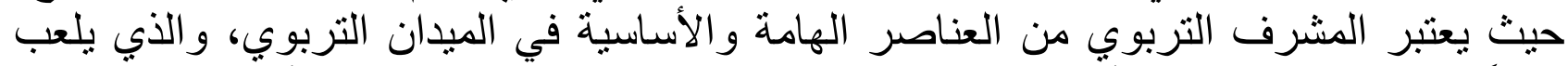

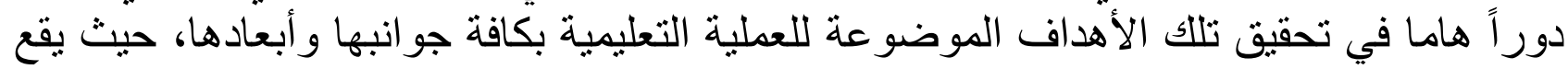

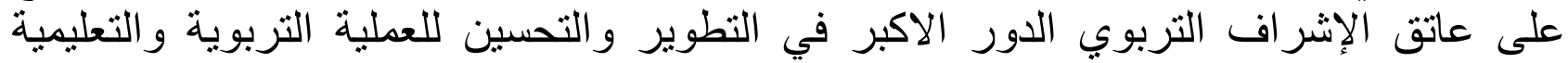

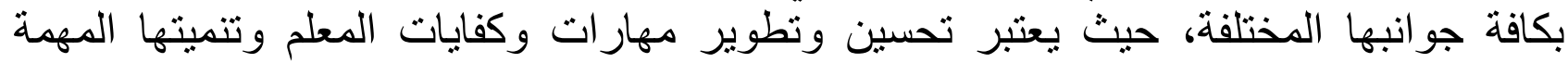

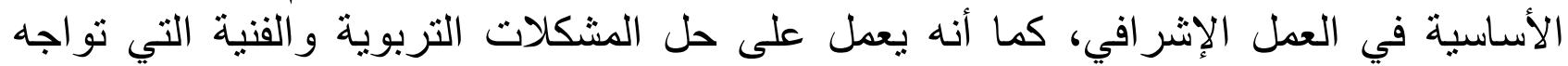

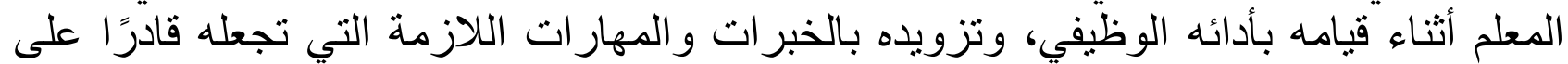

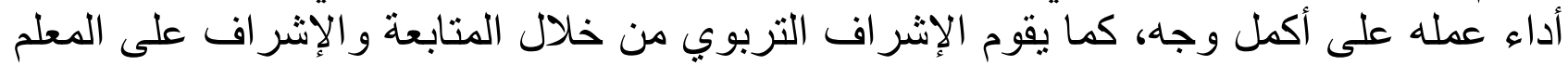

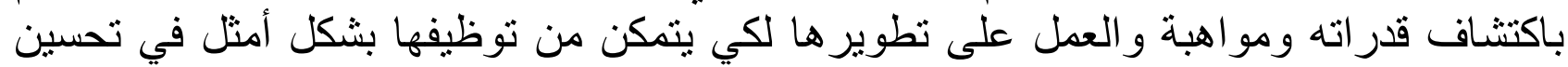
العملية التعليمية و الرقي بها (الكية ودلباني، 2016).

وكما يعد الإشراف التربوي حجر الأساس للعمليات التربوية وذللك للاور الهام والأساسي الذي التي التئي

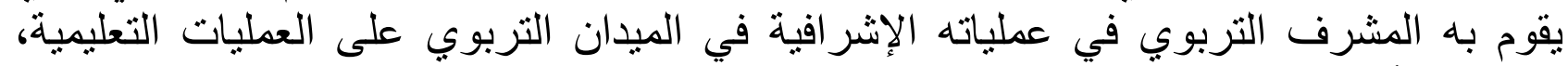

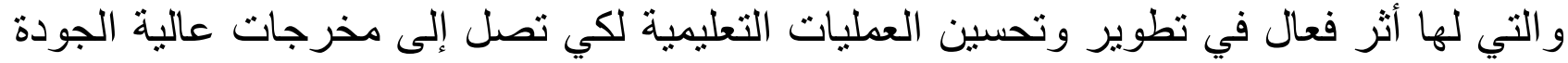

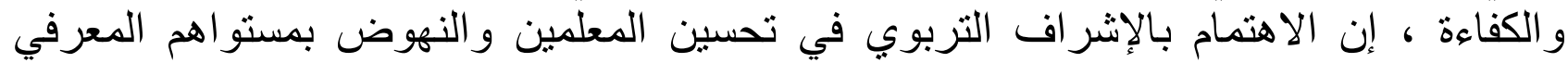

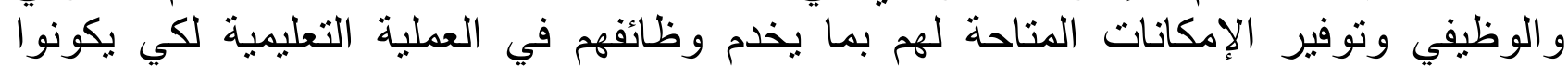

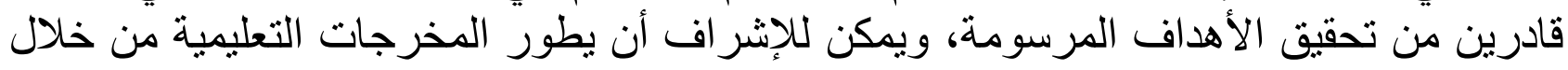




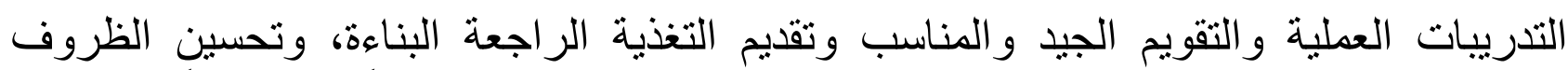

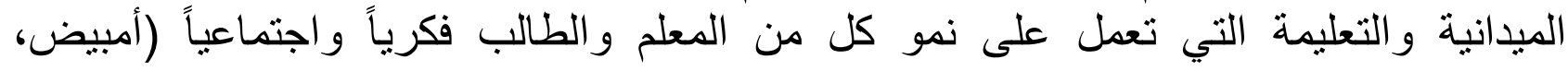

كما أن للإشراف مكانة عظيمة وراسخة كطريقة شائعة التطبيق في كل المؤسسات التعليمية

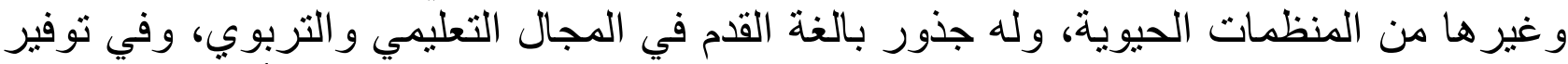

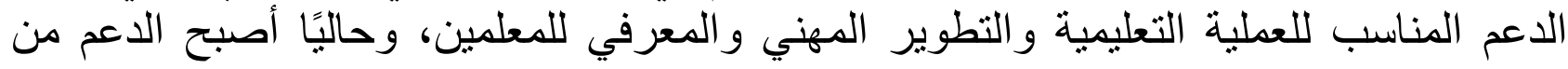

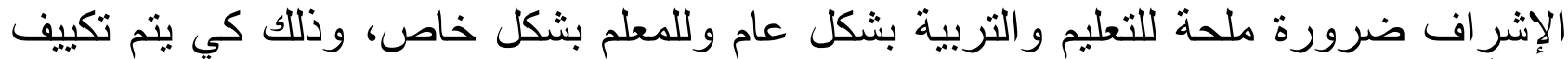

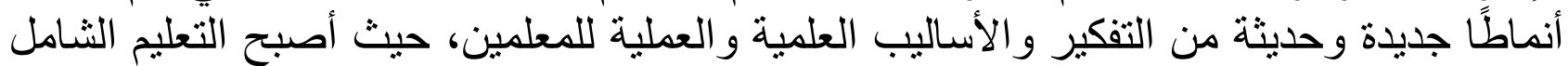

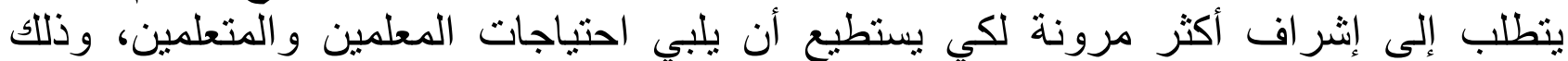

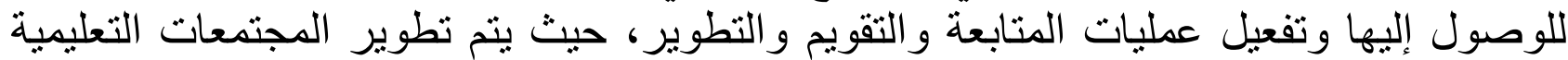

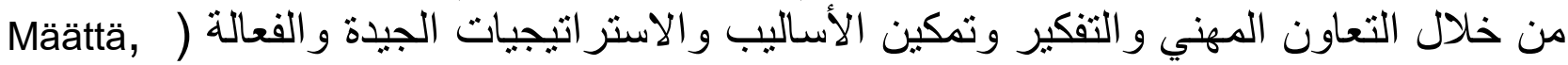
.(\& Alila, 2016

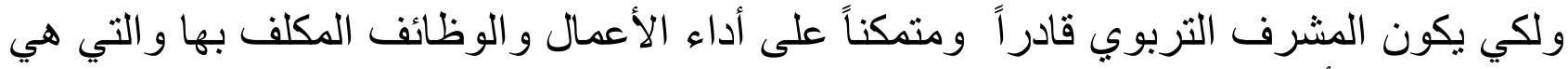

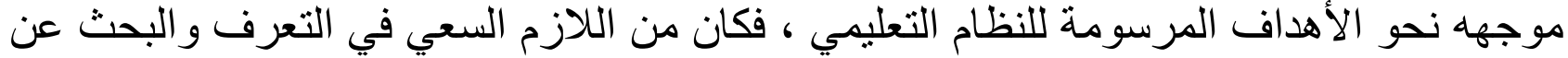

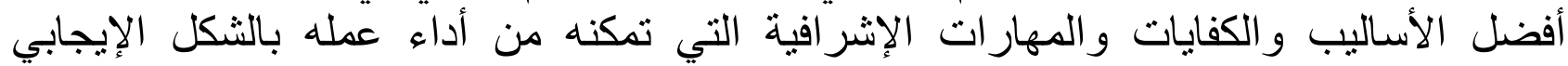

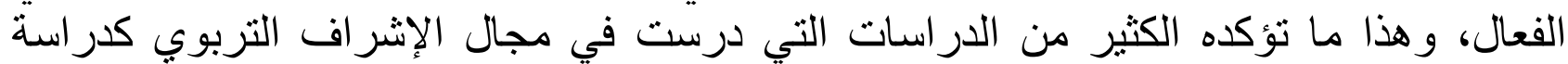

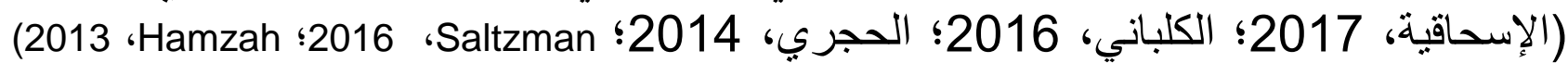
حيث أنها أوصت بضرورة الاهتمام بتدريب و العمل على تطوير المشرف التربوي الإنى بشكل دائم، وذلك من أجل تطوير الأداء الإشر افي في عمله.

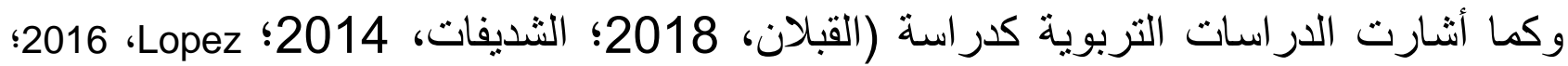
بالأفة 2013،Chen \& Cheng

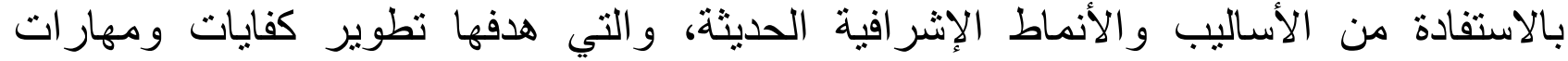
المعلمين في الحقل التربوي، و العمل على حفز هم مهنيًا وفنيًا.

وانطلاقا من الدور الذي يقوم به الإشراف التربوي في تحسين وتجويد العملية التعليمية في

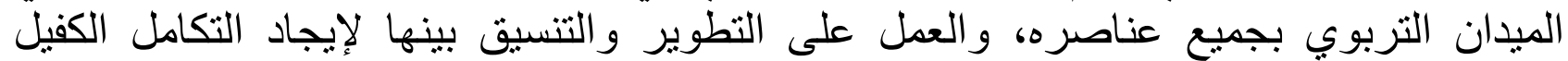

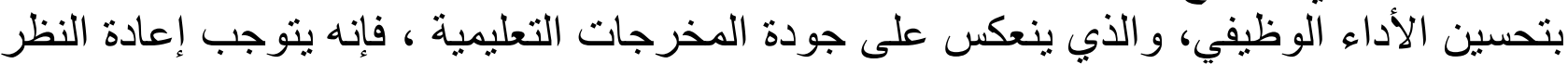

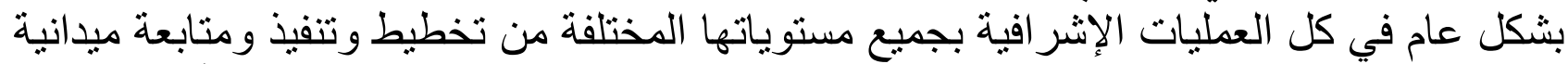
وتقويم ومناهج وغيرها من الوظائف التي يقوم بها الإشراف التهات التربوي ليكون قادراً على تقديم رسالته بشكل أفضل ومنل (وزارة التربية، 2015).

مشكلة الار اسة:

من خلال قيام الباحث بالاطلاع على الأدب النظري الذي يتحدث عن دور المشرف التربوي في

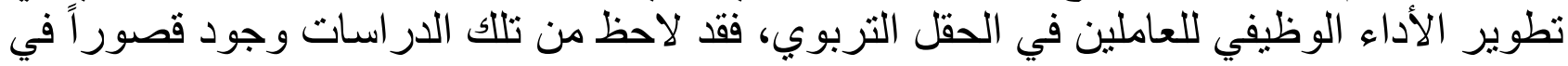

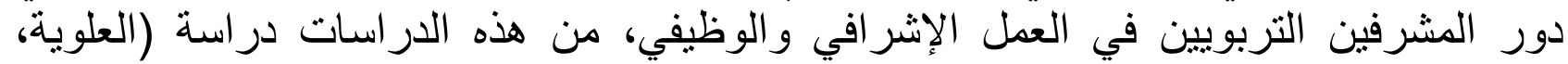

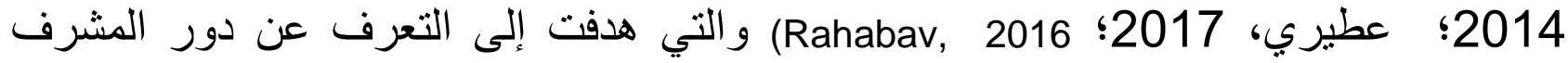




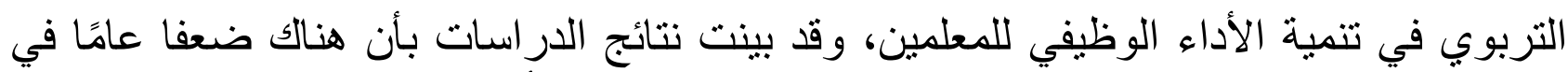

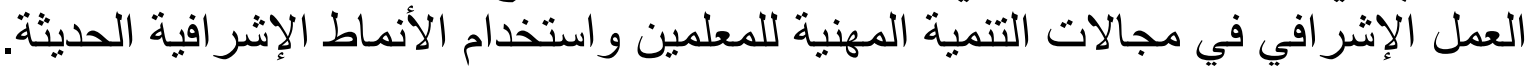

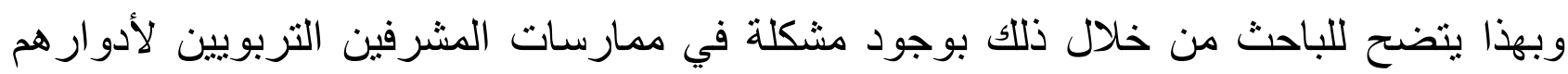

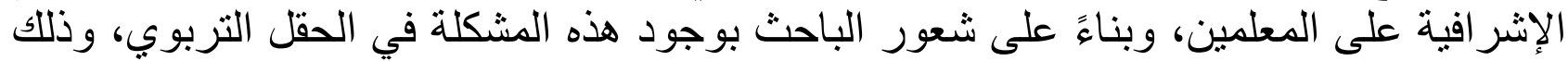

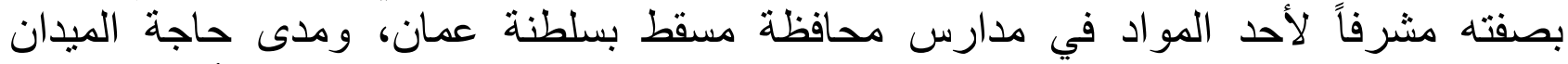

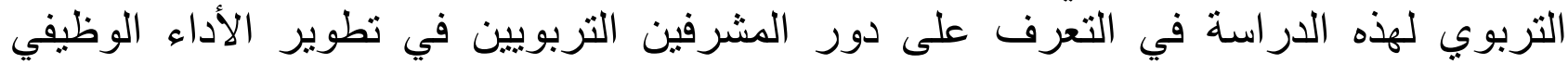

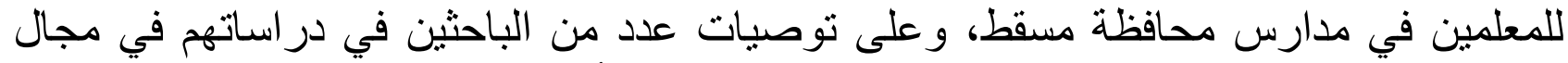

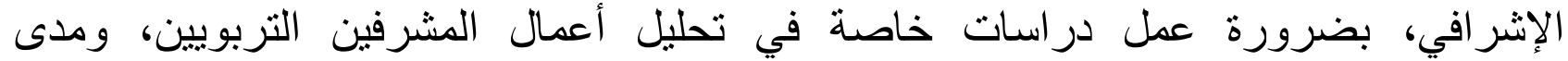

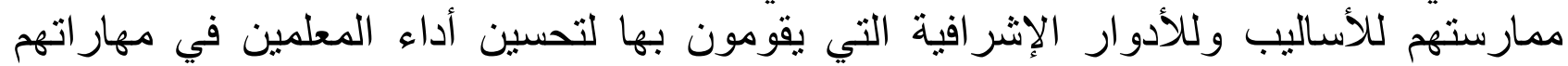

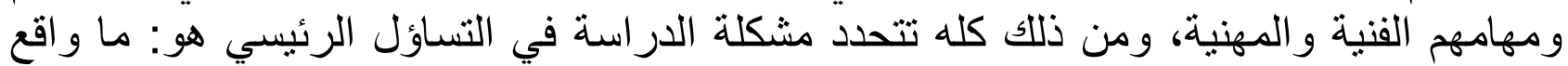
دور المشرف التربوي في تطوير الأداء الوظيفي للمعلمين في مدارس التعليم مأ بعد الأساسي

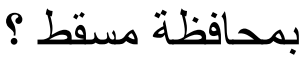

أهداف الدراسة

بناءً على أسئلة الدراسة التي وضحها الباحث في الأسطر السابقة فإنه يحاول تحقيق الأهداف

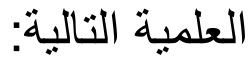

1- التعرف على و اقع قيام المشرف التربوي بدوره في تطوير الأداء الوظيفي للمعلمين بمدارس

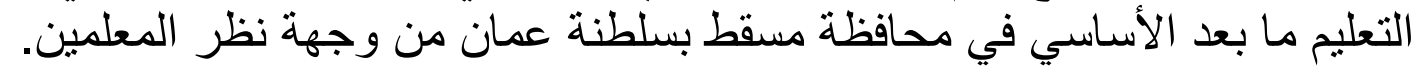

2- دراسة الفروق ذات دلاله إحصائية عند مستوى الدلالة (20.05 ه م) في متوسط تقدير

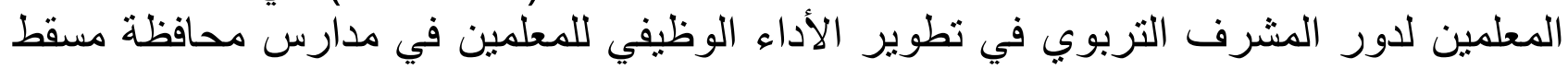

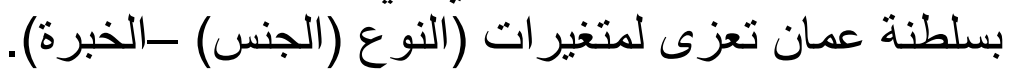

الأدات السابقة

أولاً: الاراسات العربية

وفي دراسة قطاف (2017) حيث كان الهدف من الدراسة التعرف على الدور الذي يقوم به الأبه

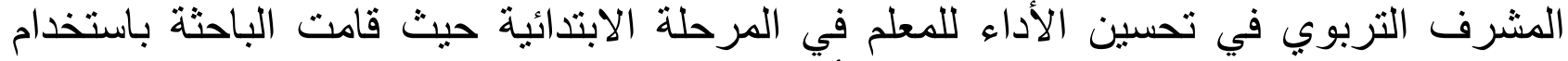

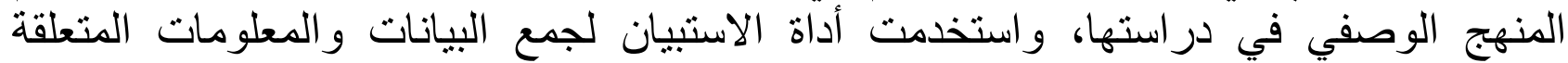

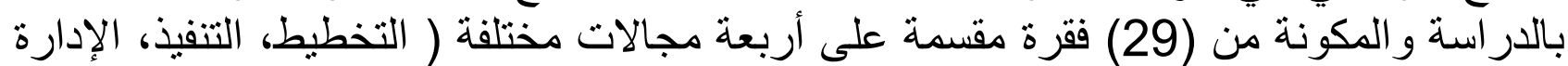

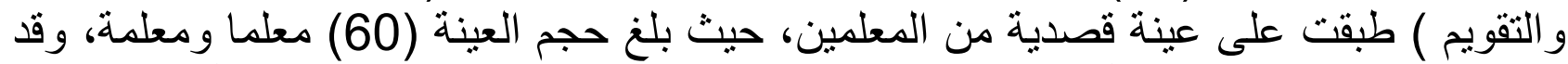

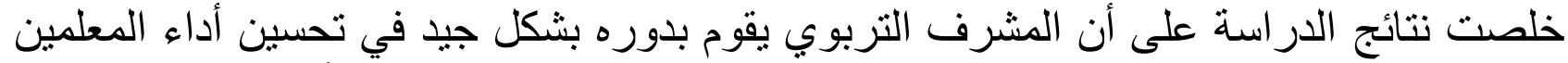

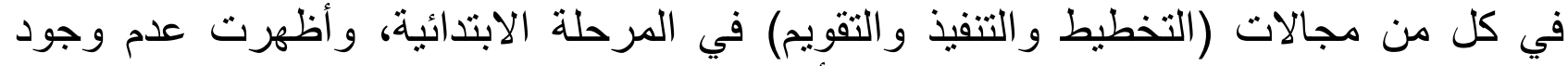
فروق ذات دلالة إحصائية لمتوسط تقديرات أفراد العينة تعزي لمتغيرات (الجنس، التخصص،

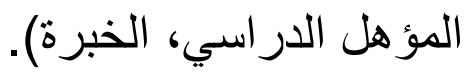
وفي دراسة دفع الله، عمار و حامد، صباح ( 2018) و التي هدفت في البحث عن واقع الإشر اف 
التربوي ودوره في تطوير بعض الكفايات لمعلمي اللغة الإنجليزية بالمرحلة الثانوية بولاية التاية

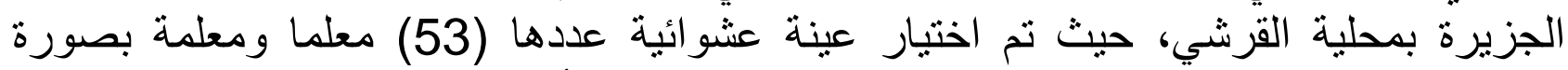

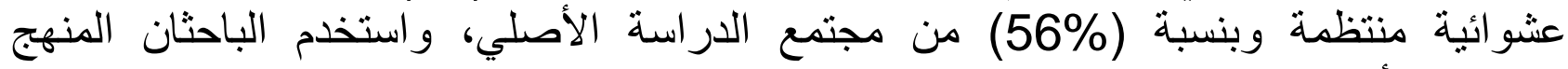

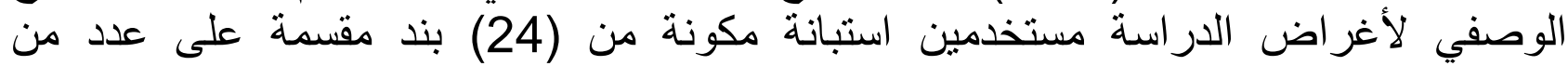

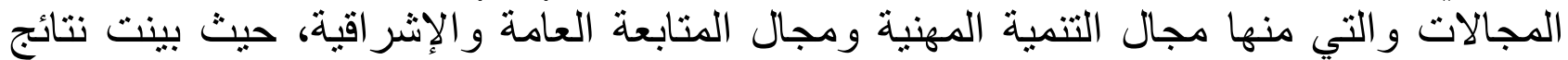

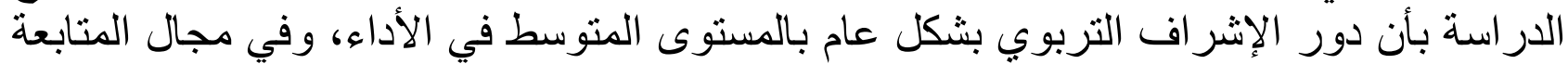

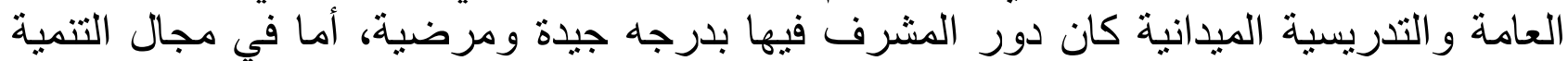

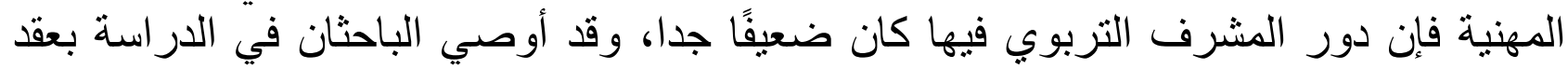

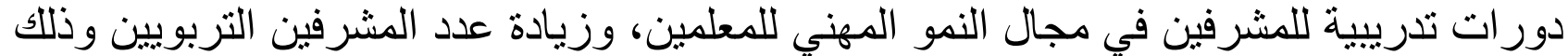

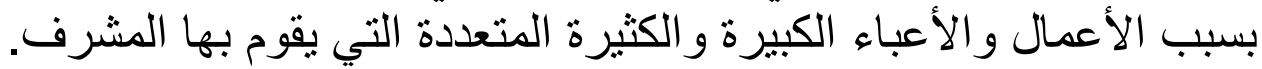

\section{ثنانياً: الدراسات الأجنبية}

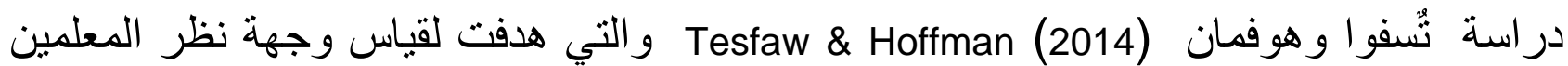

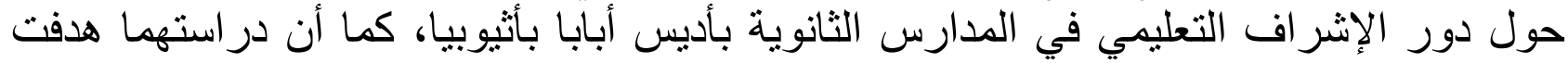

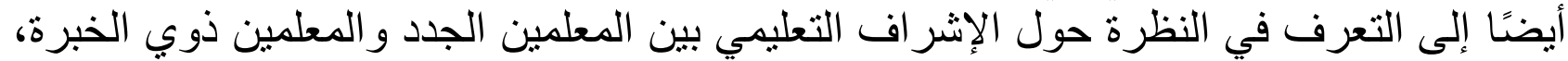

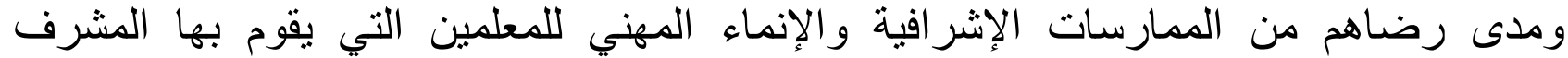

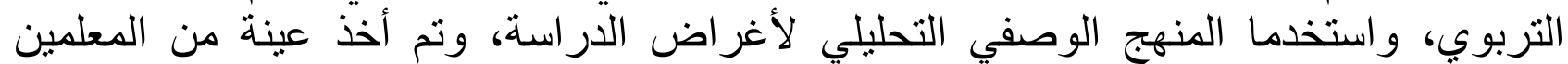

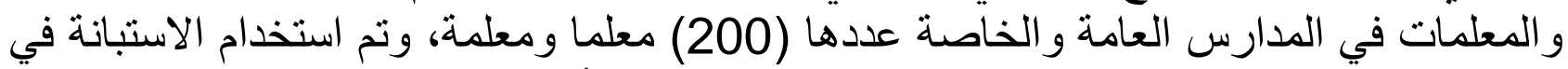

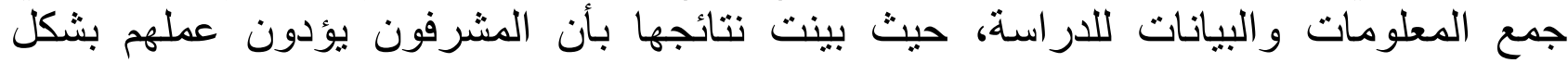

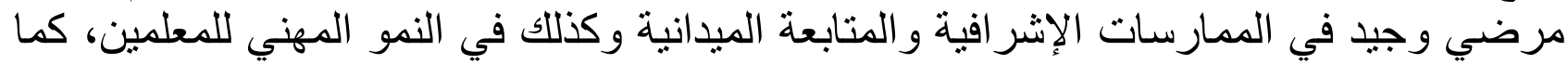

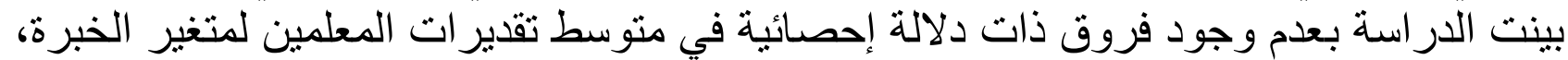

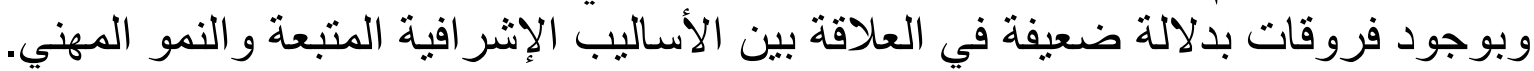

وفي الدراسة التي أقامها أبوبكر وآخرون Abubakr (2015) والتي هدفها التعرف على التى دور

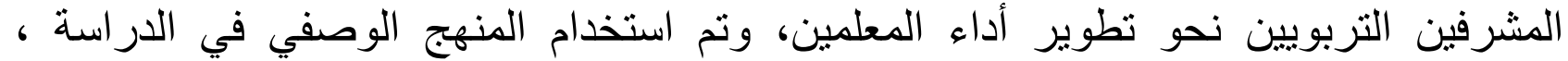

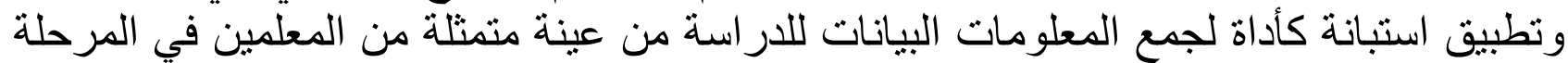

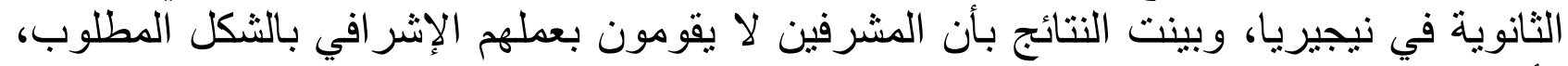

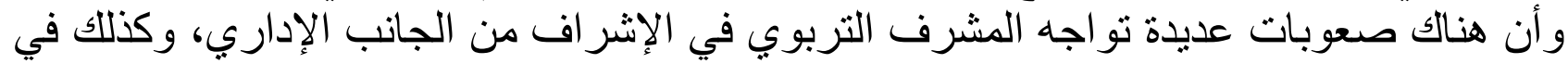

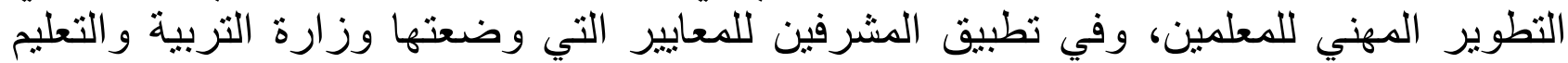

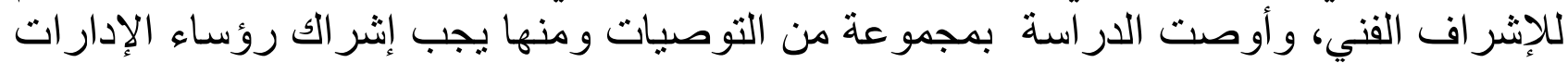

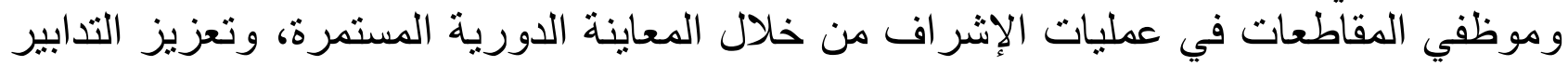

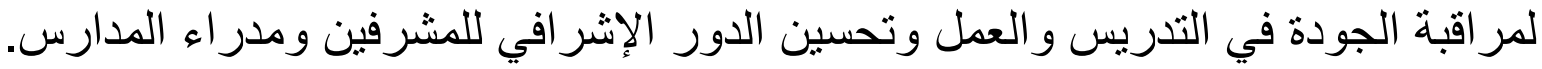

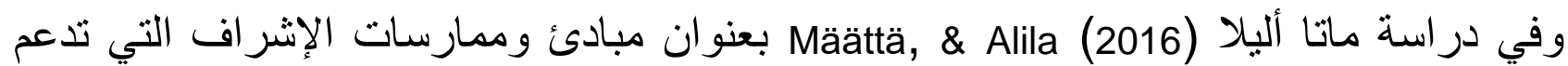

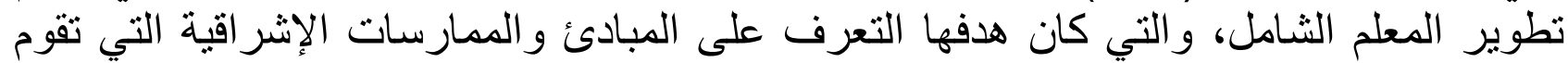

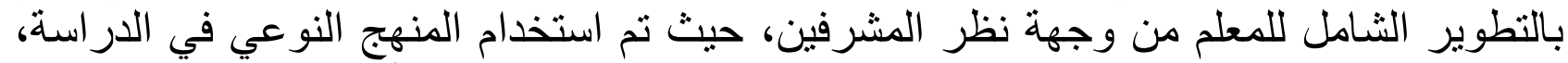
وذللك بعمل المقابلات في الحصول على المعلى المعلومات للار اسة من خمسة أماكن مختلفة في فنلندا،

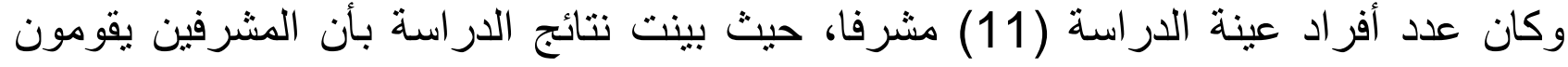


بالتخطبط الدقيق للأشراف بشكل جيد، كما أنهم بستخدمون الأساليب الإشرافية الجيدة والحديثة

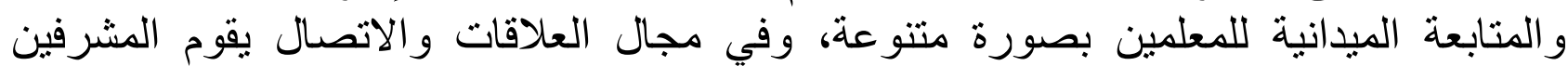
بالدعم و الاهتمام باحتياجات المعلمين وتمكين المعلمين في عملهم. منهج الاراسة وإجراع|تها:

استخدم الباحث المنهج الوصفي لأغر اض در استها، ويعرف المنهج الوصفي بأنه شكل من أشكال

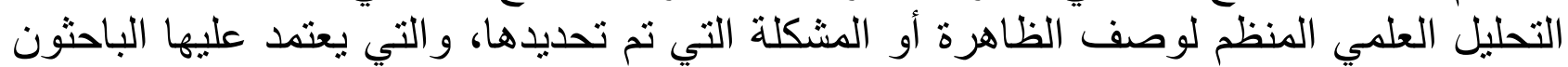

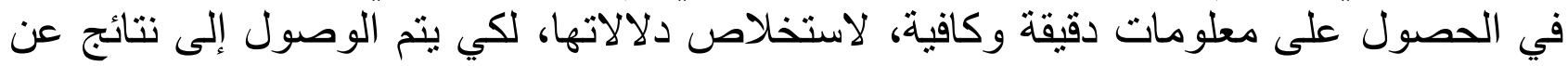

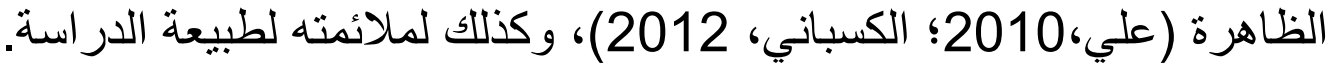

مجتمع الدراسة

تألف مجتمع الدراسة الحالية من جميع المعلمين و المعلمات في مدارس التعليم ما بعد الأساسي

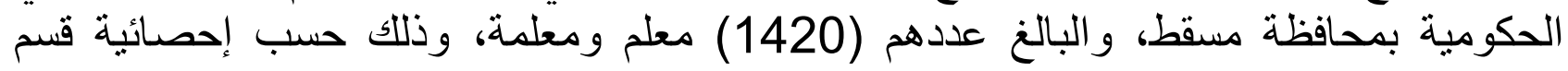

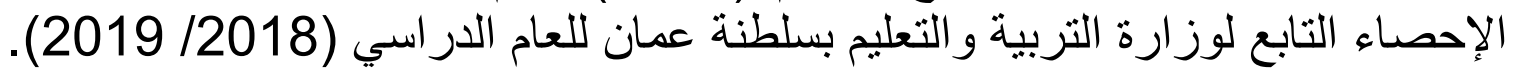

عينة الاراسة

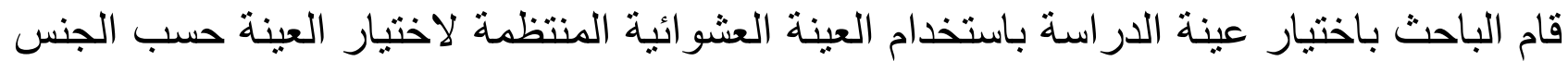

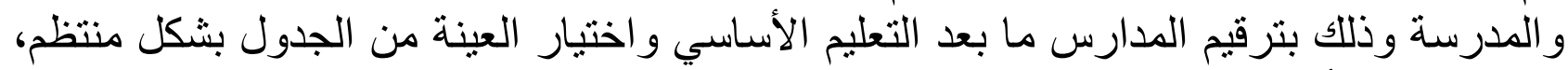

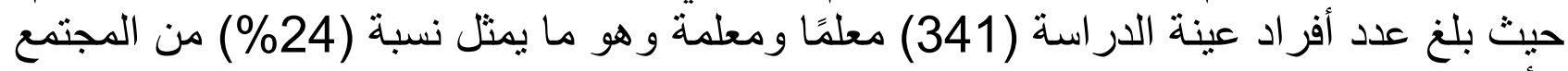
الأصلي، بو اقع (171) معلم و (170) معلمة.

جدول (1) خصائص عينة الدر اسة تبعًا لمتغيري (الجنس و الخبرة)

\begin{tabular}{|c|c|c|c|c|}
\hline النسبة المئوية & المجموع & العدد & فئات المتغير & المتغير \\
\hline $\begin{array}{l}\% 50 \\
\% 50\end{array}$ & 341 & $\begin{array}{c}171 \\
170\end{array}$ & أنثى ذكر & الجنس \\
\hline $\begin{array}{c}\% 23 \\
\% 38 \\
\% 39\end{array}$ & 341 & $\begin{array}{c}80 \\
128 \\
133\end{array}$ & أكثر من إلى 10 سنو سنوات 5 سنوات 10 سنو 10 ات & ' الخبرة \\
\hline
\end{tabular}

أداة الدراسة

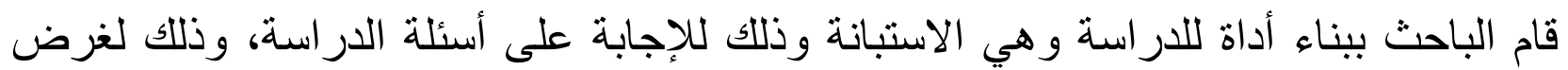

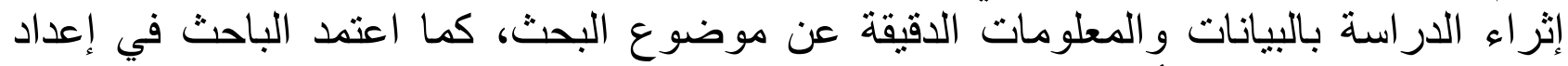

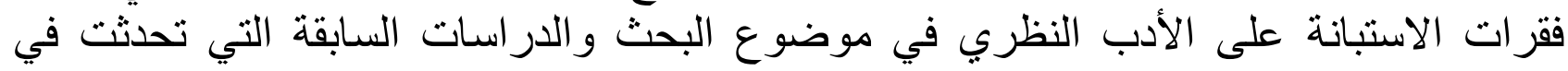

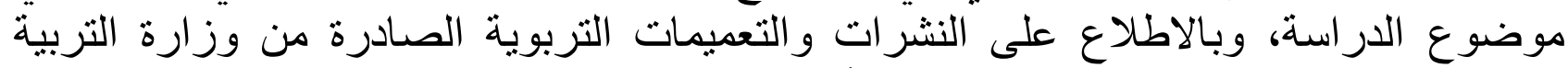

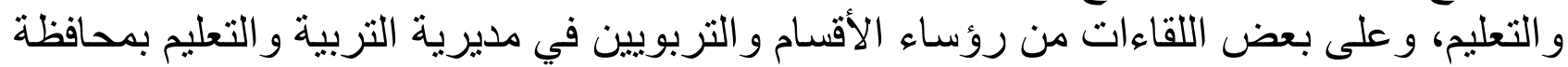

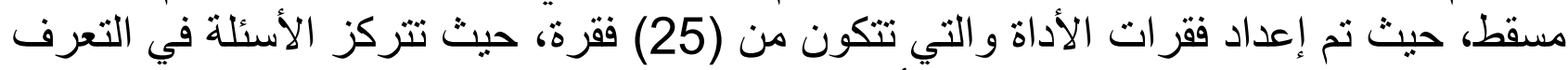
على دور المشرف التربوي في تطوير الأداء الوظيفي للمعلمين في خمسة مجالات مختات منلفة. 
ولكي يتحقق الباحث من صدق الأداة الظاهري، فقد تم عرضها على مجموعة من المختصين

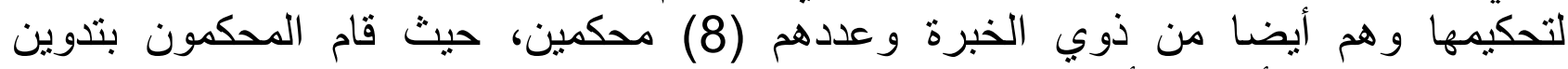

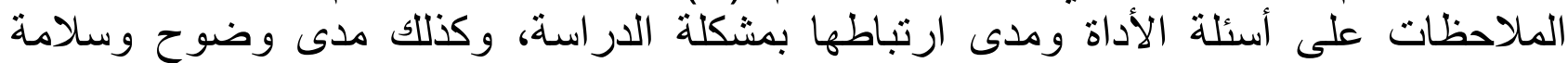

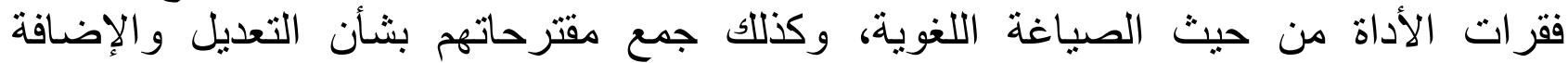

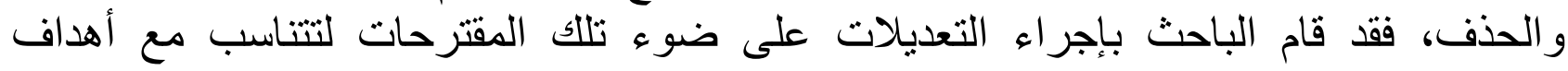

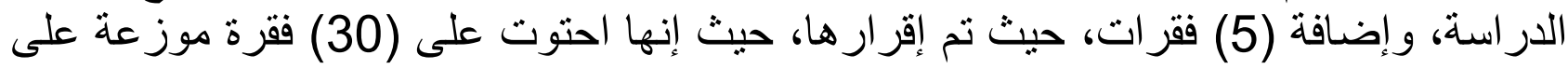
خمسة مجالات.

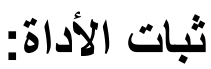

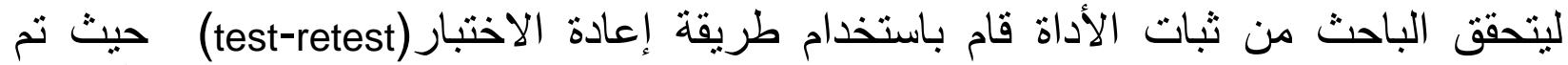

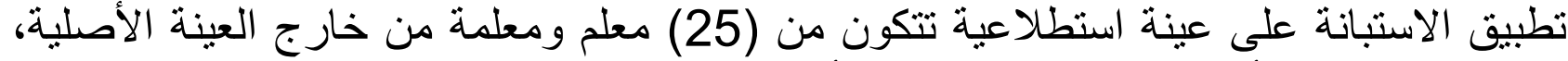

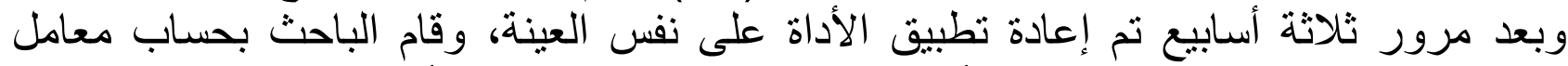

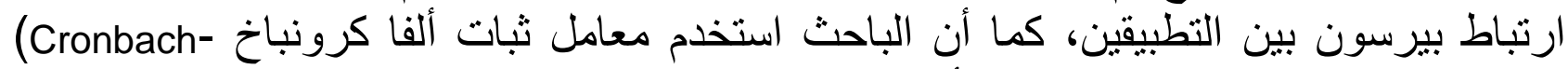
Alpha) جدول (2) معاملات ثبات وارتباط أداة الدراسة

\begin{tabular}{|c|c|c|c|}
\hline معامل ارتباط & معامل كرونباخ & المجال & الرقم \\
\hline & & بيرسون & \\
\hline 0,90 & 0,82 & العلاقات الإنسانية & 1 \\
\hline 0,88 & 0,85 & التدريب و النمو الههني & 4 \\
\hline 0,79 & 0,87 & التخطيط & 2 \\
\hline 0,85 & 0,97 & التقويم & 5 \\
\hline 0,86 & 0,88 & المتابعة الميدانية & 3 \\
\hline 0,88 & 0,86 & الارجة الكلية & \\
\hline
\end{tabular}

يبين الجدول السابق أن أداة الدراسة تتمتع بدرجات ثبات ومعاملات ارتباط جيدة، حيث بلغ

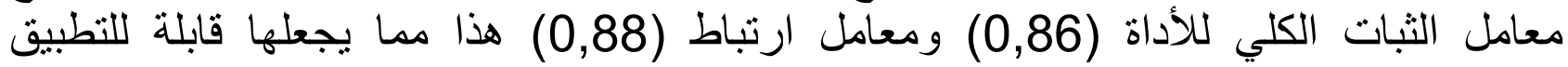
الميداني. طريقة تقدير الدرجات

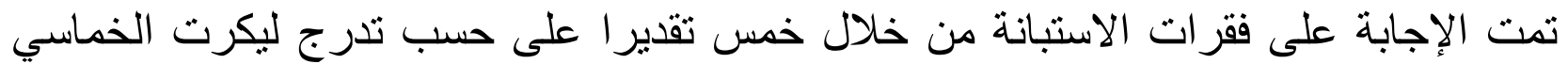

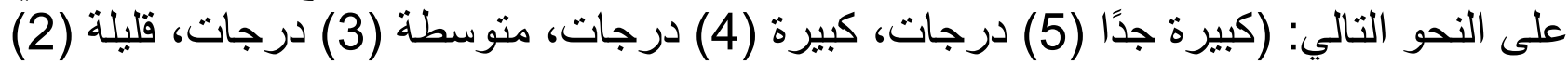

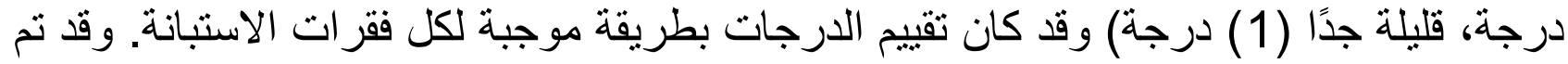

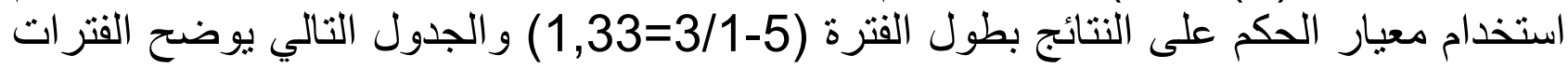

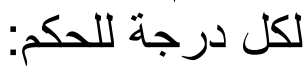




\section{جدول (3) يوضح فترات المتوسط الحسابي للفقرة أو المجال ودرجة الحكم عليها}

\begin{tabular}{|c|c|c|}
\hline درجة & المتوسط الحسابي & \\
\hline قليلة & من (1) إلى أقل من (2,33) & 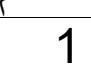 \\
\hline$(3,68)$ & من (2,33) إلى أقل من & 2 \\
\hline 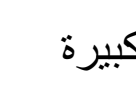 & من (3,68) (الى (5) & 3 \\
\hline
\end{tabular}

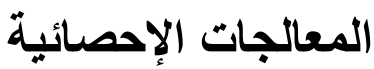

تمت معالجة البيانات باستخدام البرنامج "SPSS" على الحاسوب، وذلك للإجابة على أسئلة الار اسة: 1- معامل الارتباط لبيرسون، ومعادلة ألفا كرونباخ للتحقق من ثبات الأداة. 2- للإجابة على السؤال الأول نم حساب المنوسطات الحسابية والانحر افات المعيارية و إيجاد

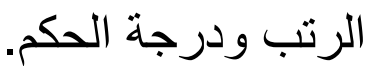
3- وللإجابة على السؤال الثاني قام الباحث باستخدام الاختبار الثنائي (t-teSt) للعينات المستقلة لكتغير الجنس، وكذلك تحليل التباين الأحادي (ANOVA) للفرق تبعًا لتنغير الخبرة.

عرض النتائج وتفسيرها

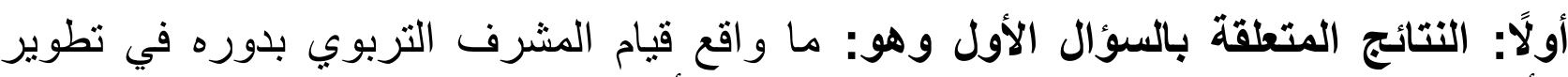

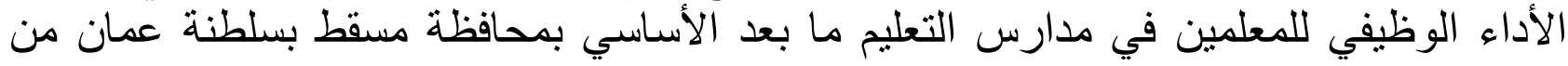

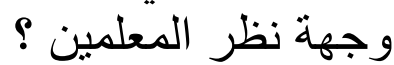

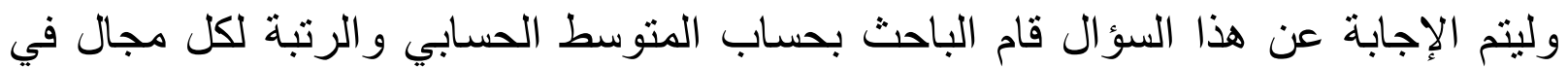

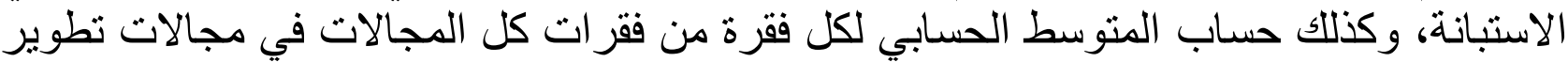

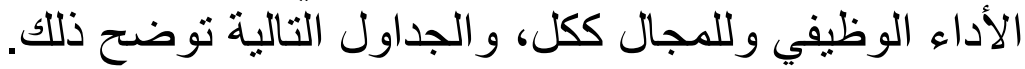

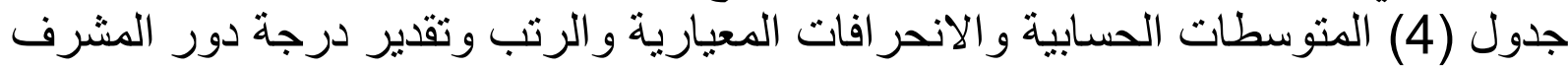

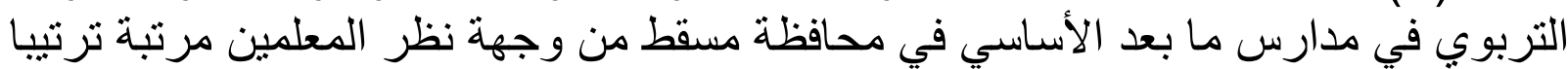
تنازليا

\begin{tabular}{|c|c|c|c|c|}
\hline الرتبة & الانحراف المعياري & المتوسط الحسابي & تقدير اللارجة & |الرقم : \\
\hline 1 & 0,62 & كبيرة 3,99 & العلاقات الإنسانية & \\
\hline 2 & 0,82 & 3,63 & التدريب و النمو المهني & 2 \\
\hline
\end{tabular}




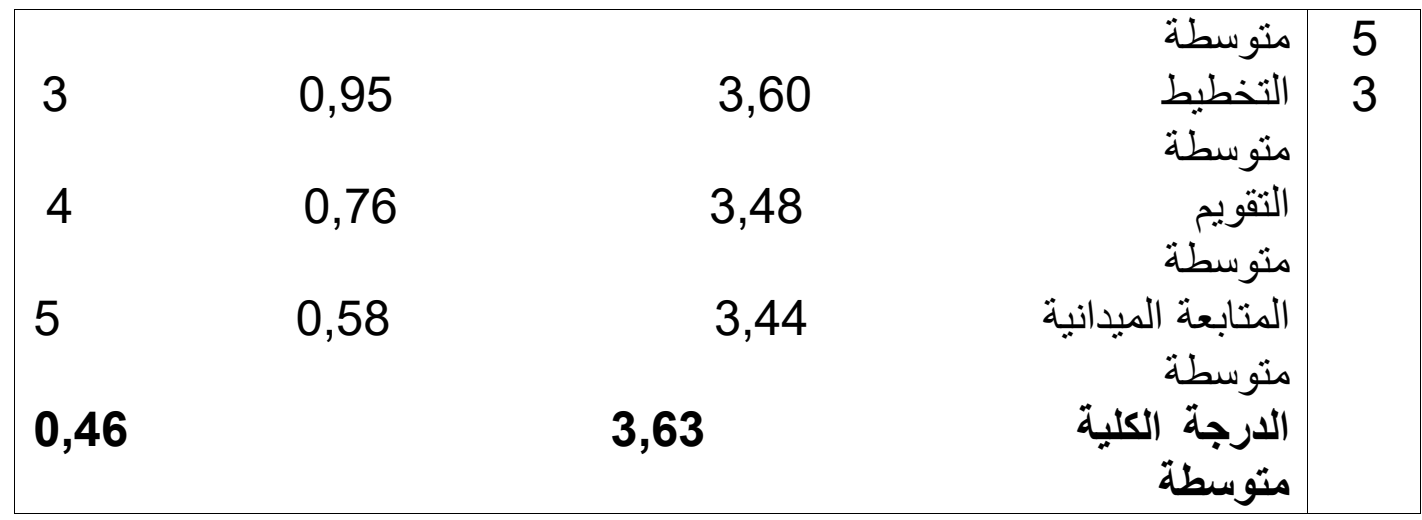

تضح من الجدول (4) أن تقدير أفراد العينة لدور المشرف التربوي في تطوير الأداء الوظيفي

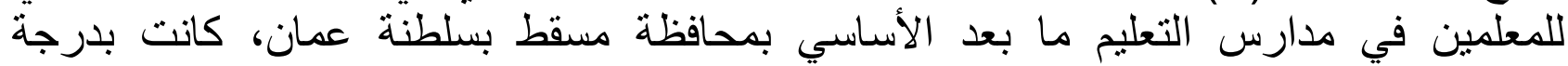

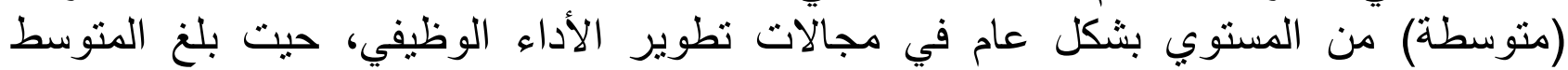

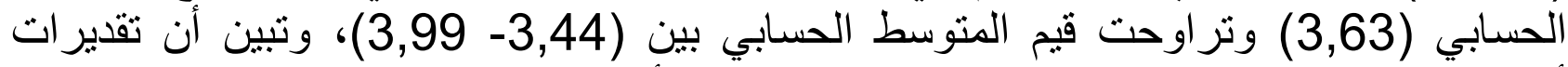

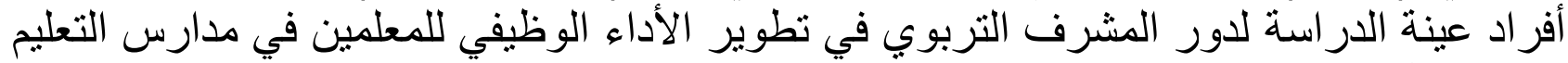

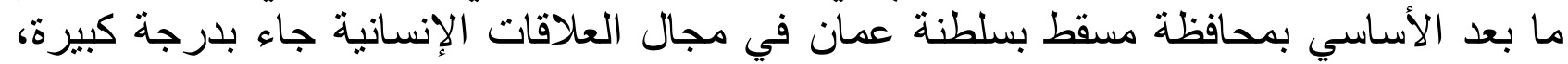

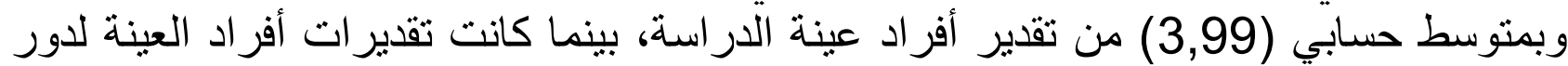

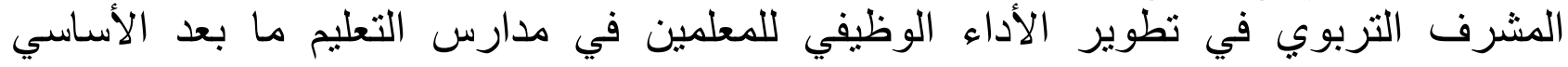

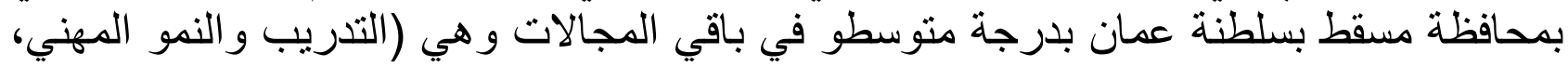

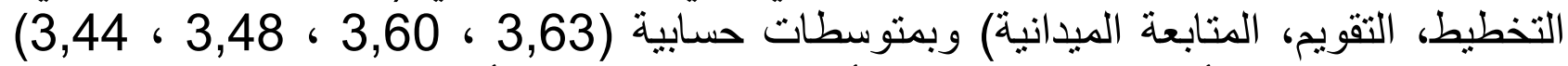
على الترتيب. ويمكن أن تفسر هذه النتيجة بأن مجالات التطوير للأداء الوظيفي للمعلمين متئ متداخلة

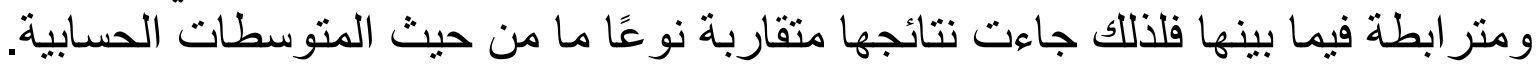

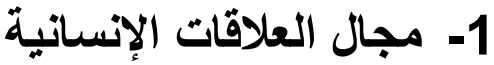

تم حساب المتوسطات الحسابية والانحر افات المعيارية والرتب ومستوى الدرجية دوبة دور

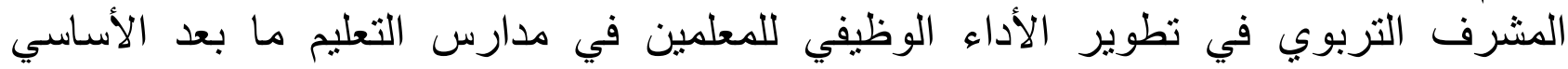

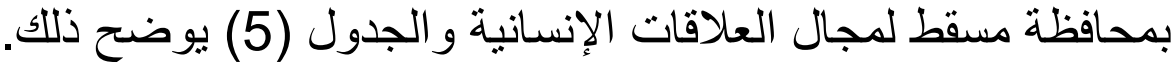

جدول (5) المتوسطات الحسابية والانحر افات المعيارية والرتب ودرجة دور المشرف التربوي لمجال العلاقات الإنسانية مرتبة ترنيبا تنازليا

\begin{tabular}{|c|c|c|c|c|}
\hline الرتبة & 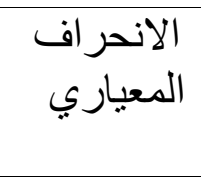 & 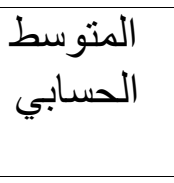 & المستوى & الرقم \\
\hline 1 & 0,63 & 4,22 & كيبرة في حل المشكلات بين المعلمين & $\begin{array}{l}2 \\
1\end{array}$ \\
\hline 2 & 0,73 & 4,06 & كبيرة ببناء علاقات إيجابية مع الإدارة و المعلمين & $\begin{array}{l}5 \\
4\end{array}$ \\
\hline 3 & 0,86 & 4,02 & كبيربل وجهات نظر المعلمين & $\begin{array}{l}6 \\
3\end{array}$ \\
\hline
\end{tabular}




\begin{tabular}{|c|c|c|c|}
\hline 4 & 0,88 & 3,96 & يتعامل مع المعلمين بموضو عية و عدالة \\
\hline 5 & 0,86 & 3,94 & كبشارك في الفعاليات بالمدرسة \\
\hline 6 & 1,00 & 3,62 & ير اعي حاجات المعلمين الثخصية \\
\hline 0,62 & & & الدرجة الكلية \\
\hline
\end{tabular}

يتضح من الجدول (5) أن تقدير ات أفراد عينة الدراسة لدور المشرف التربوي في تطوير

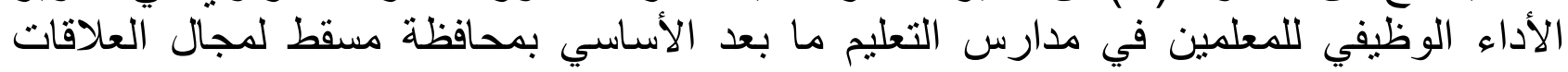

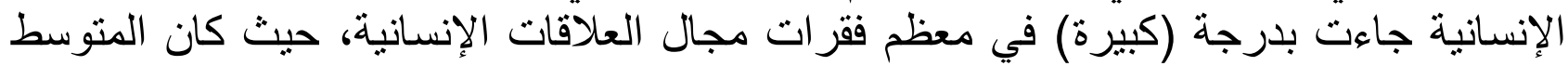

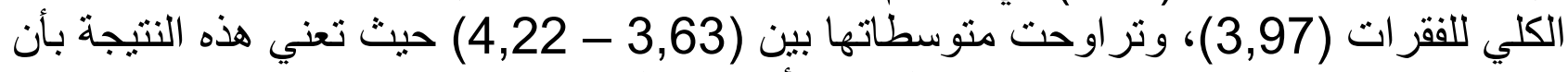

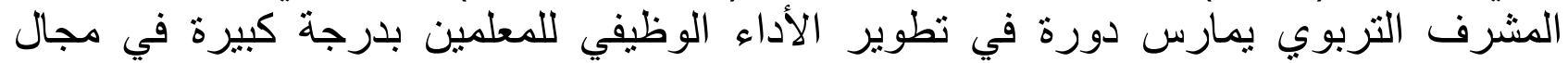

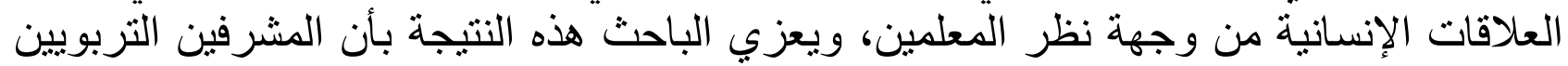

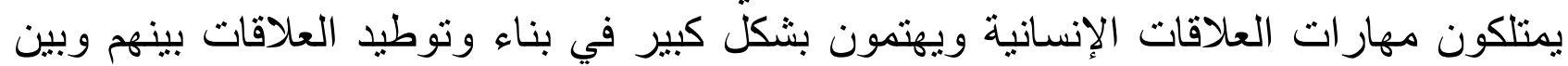

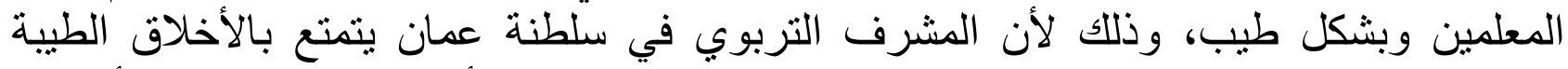

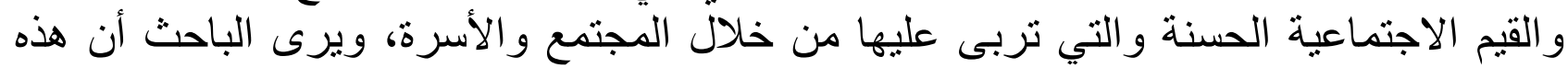

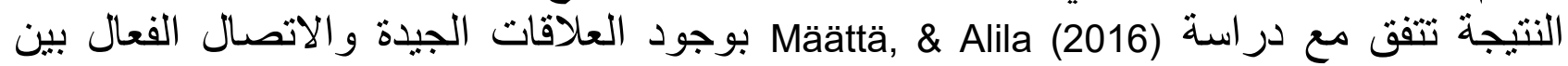
المشرفين و المعلمين.

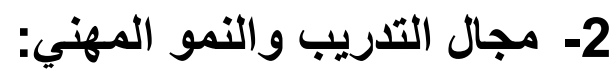

تم حساب المتوسطات الحسابية والانحر افات المعيارية والرتب ومستوى الدرجة دوبة دور المشرف

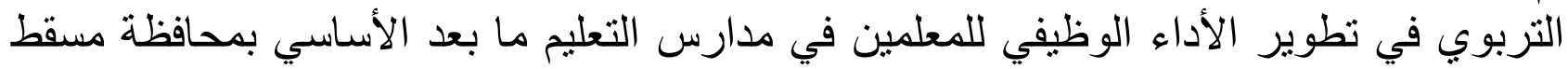

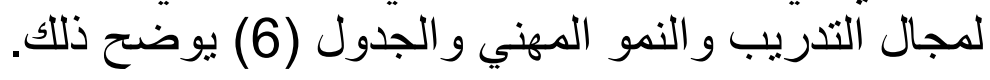

جدول (6) المتوسطات الحسابية والانحر افات المعيارية والرتب ومستوى الدرجة لدور المشرف

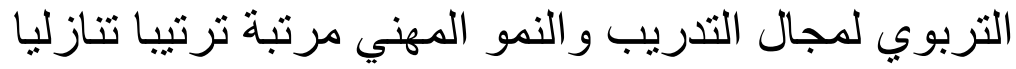

\begin{tabular}{|c|c|c|c|c|}
\hline الرتبة & المعياري & المسابي & المستوي & الرقم \\
\hline 1 & 0,83 & 3,84 & كبيرة على تنفيذ برامج تدرييية للمعلمين وفق الاحتياجات. & $\begin{array}{l}23 \\
21\end{array}$ \\
\hline 2 & 0,80 & 3,75 & كبيرة كي في تحديد البر امج للتنمية المهنية . & $\begin{array}{l}22 \\
20\end{array}$ \\
\hline 3 & 0,90 & 3,71 & كبيرة الاحتياجات التدريبية للمعلمين. & 24 \\
\hline 4 & 1,06 & 3,53 & متوسطعة المعلمين على مو اصلة نمو هم المهني. & 19 \\
\hline
\end{tabular}




\begin{tabular}{|c|c|c|c|}
\hline 5 & 1,05 & 3,51 & يثت سطع المعلمين على الاستفادة من التجارب التربوية. \\
\hline 6 & 0,90 & 3,43 & يتابع الدور ات التدريبية المقدمة للمعلمين. \\
\hline & 0,81 & 3,63 & الارجة الكلية \\
\hline
\end{tabular}

يتضح من الجدول (6) أن تقديرات أفر اد عينة الدراسة لدور المشرف التربوي في تطوير الأداء

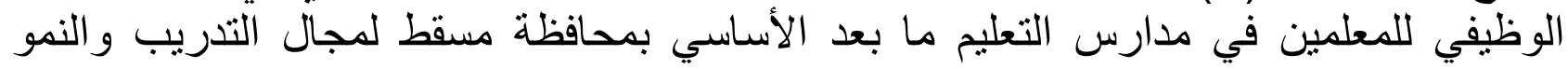

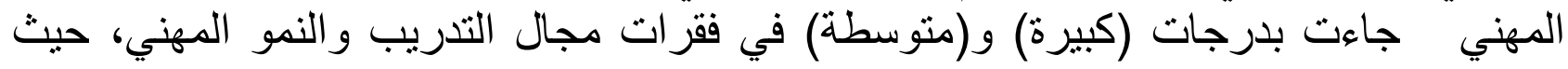

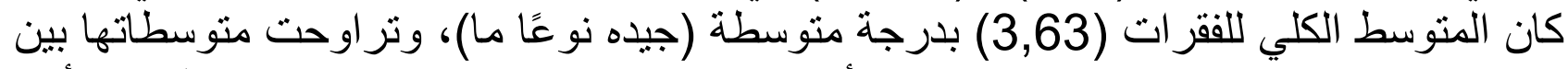

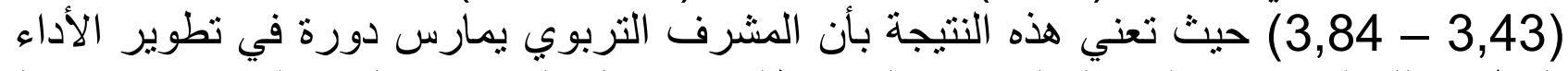

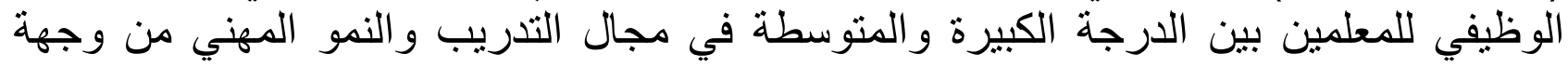

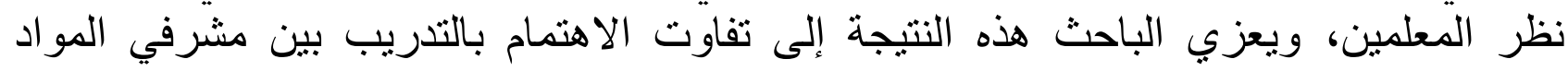

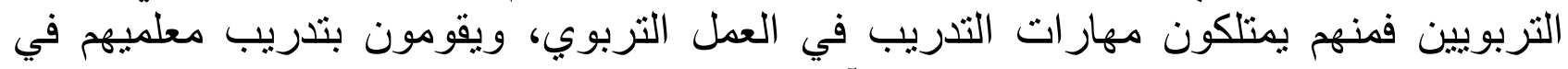

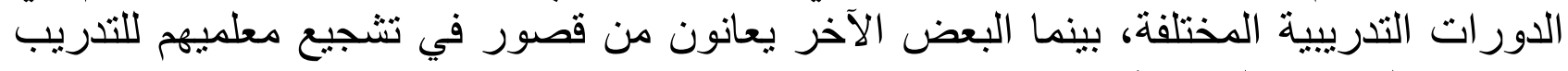
وحضور الدورات الندرية التدريبية.

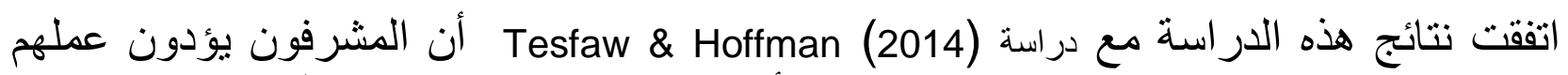

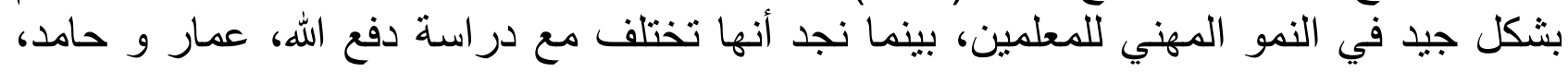

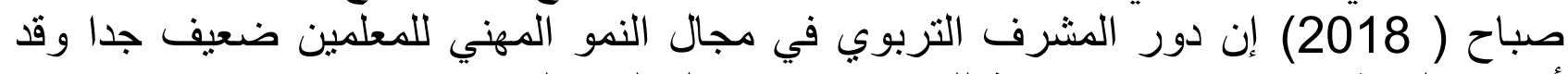

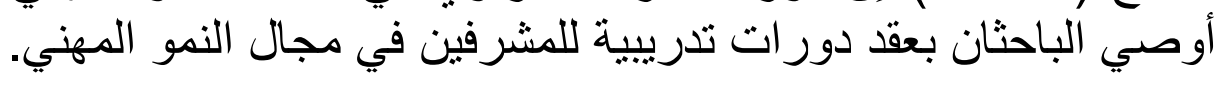

3- مجال التخطيط

تم حساب المتوسطات الحسابية والانحر افات المعيارية والرتب ومستوى الدرجة دئة دور

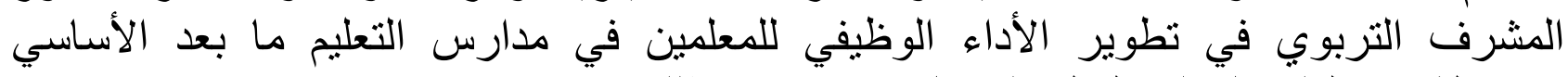

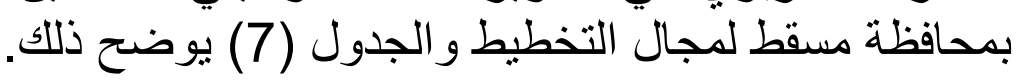

جدول (7) المنوسطات الحسابية والانحر افات المعيارية والرتب ومستوى درجة دور المشرف ترفي التربوي لمجال التخطيط مرتبة ترنيبا تناز ليا

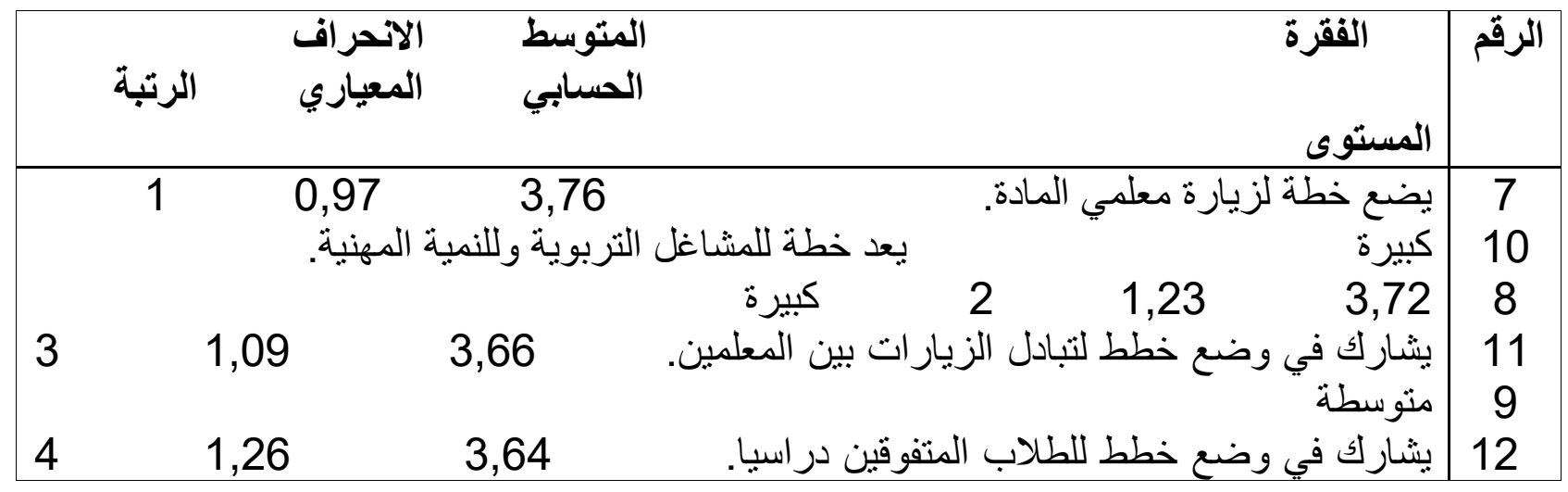




\begin{tabular}{|c|c|c|c|}
\hline & & & متوسطة \\
\hline 5 & 1,16 & 3,52 & متوسطاعد المعلمين في عمل السجلات المتعلقة بالمادة. \\
\hline 6 & 1,30 & 3,33 & منشاركة في وضع خطط للطلاب ضعيفي المستوى. \\
\hline 0,96 & & & متوسطة الارجة الكلية \\
\hline
\end{tabular}

يتضح من الجدول (7) أن تقديرات أفر اد عينة الدراسة لدور المشرف التربوي في تطوير الأداء

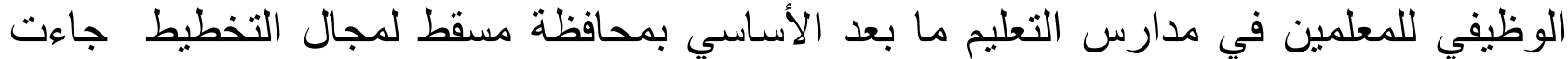

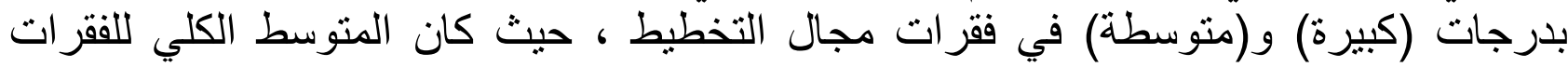

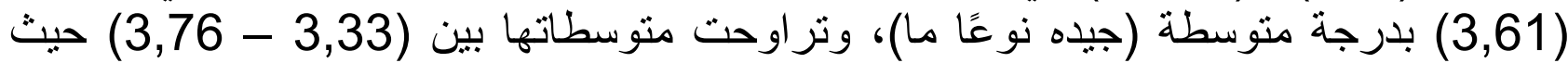

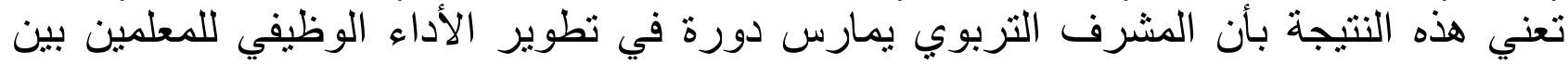

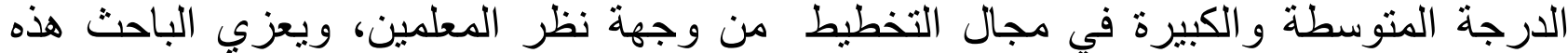

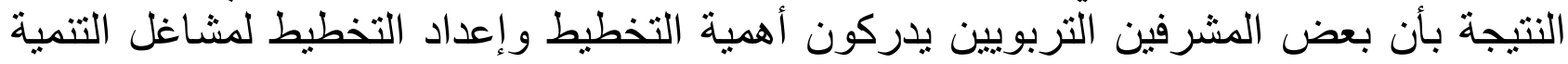

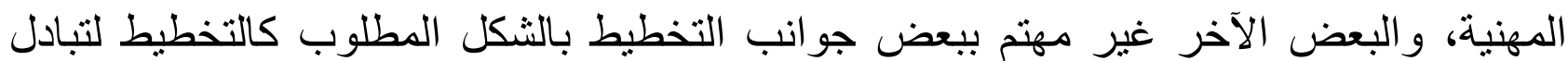

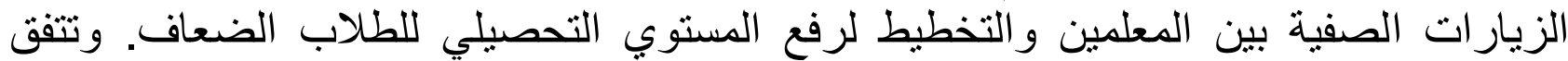

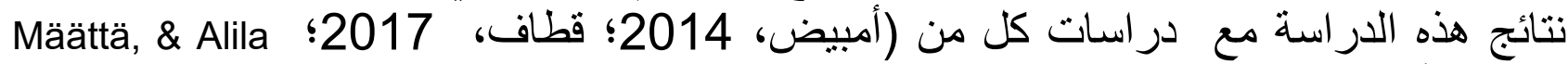
2016,) بأن المشرفين يقومون بالتخطيط بشكل جيد.

4- - مجال التقويم والاختبارات

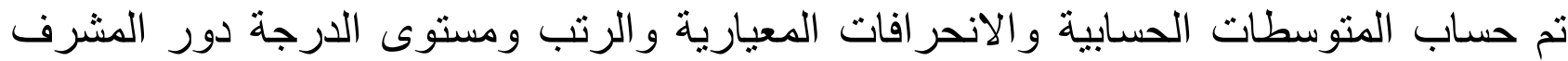

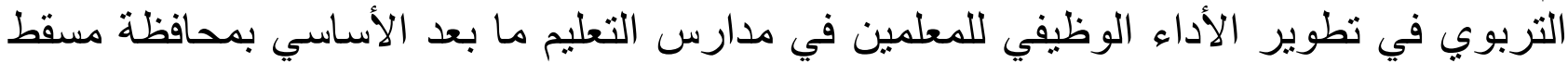
لمجال التقويم والاختبار ات و الجدول (8) يوضح ذلاء للك.

جدول (8) المتوسطات الحسابية و الانحر افات المعيارية والرتب ومستوى درجة دور المشرف التربوي لمجال التقويم مرتبة ترنيبا تنازليا

\begin{tabular}{|c|c|c|c|c|}
\hline الرتبة & المعياري & الحستوسط & المستوى & الرقم \\
\hline 1 & 0,86 & 3,81 & كبيرة التغذية الر اجعة للمعلمين & $\begin{array}{l}26 \\
25\end{array}$ \\
\hline 2 & 1,01 & 3,59 & متومطة أداء المعلمين بشكل منتظم & $\begin{array}{l}30 \\
27\end{array}$ \\
\hline 3 & 1,03 & 3,51 & متوسطةن مع المعلمين في تحليل نتائج الاختبار ات & $\begin{array}{l}29 \\
28\end{array}$ \\
\hline 4 & 0,83 & 3,47 & متوسطع المعلمين على توظيف التقويم المستمر & \\
\hline 5 & 1,04 & 3,47 & يشرف على سير أعمال الاختبار ات & \\
\hline
\end{tabular}




\begin{tabular}{|lrr|r|}
\hline متوسطة \\
6
\end{tabular}

يتضح من الجدول (8) أن تقديرات أفراد عينة الدر اسة لدور المشرف التربوي في تطوير الأداء

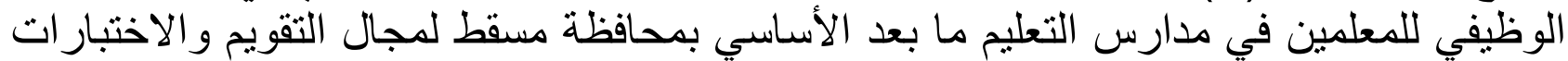

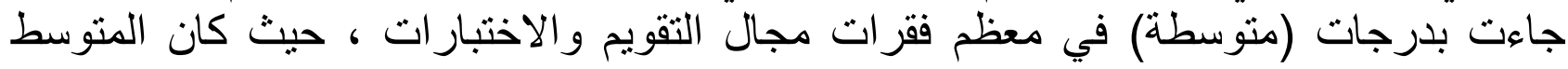

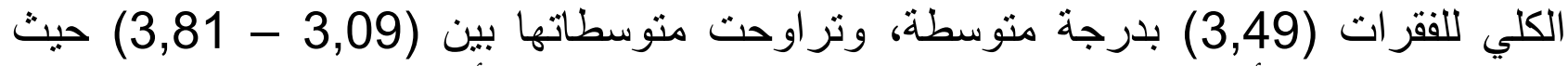

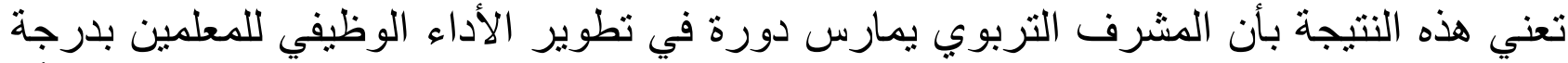

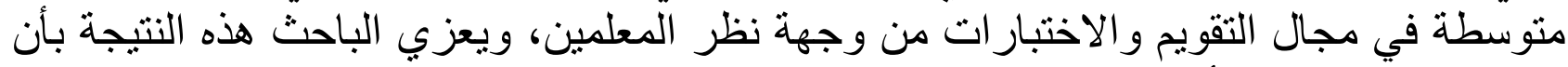

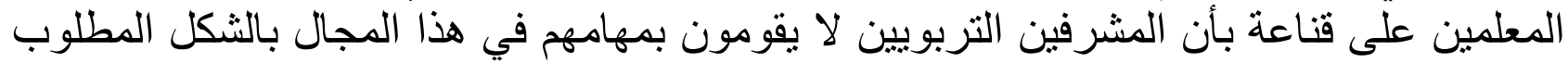

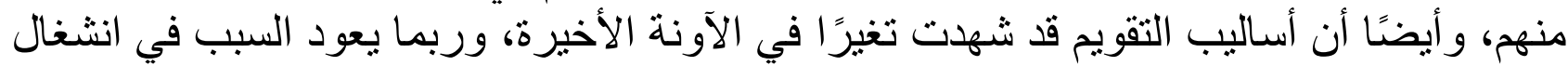

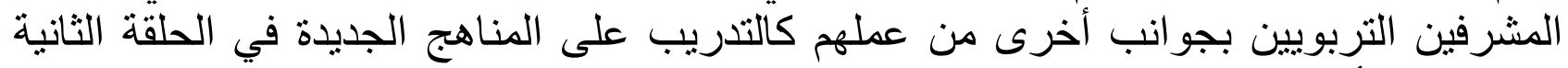
من التعليم الأساسي.

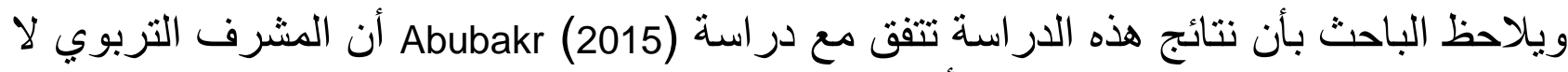

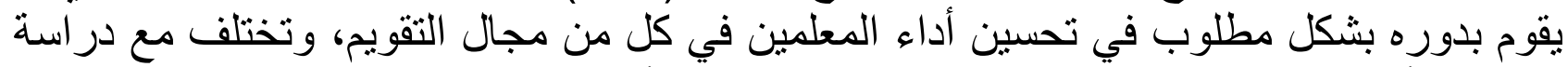

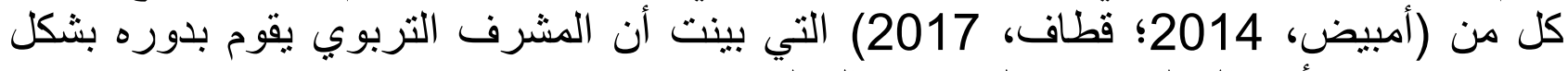
جيد في تحسين أداء المعلمين في كل من مجال التقويم.

\section{5- - مجال المتابعة الميدانية}

تم حساب المتوسطات الحسابية والانحر افات المعيارية والرتب ومستوى الدرجة الإبة دور

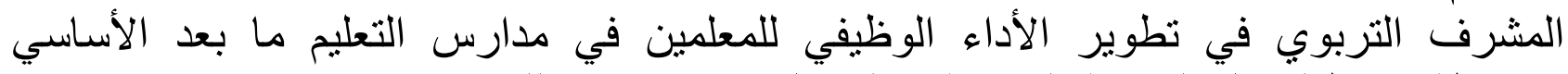

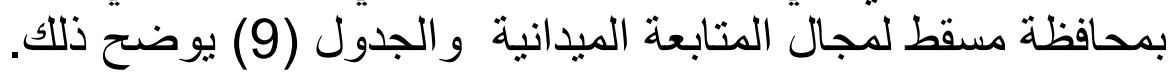

جدول (9) المتوسطات الحسابية والانحر افات المعيارية والرتب ومستوى درجة دور المشرف

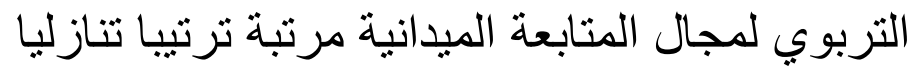

\begin{tabular}{|c|c|c|c|c|c|}
\hline & الرتبة & الانحراف المعياري & المستوسطي & المستوى القرة & الرقم \\
\hline & 1 & 1,09 & 3,52 & متوسطع سجلات معلمي المادة & $\begin{array}{l}13 \\
17\end{array}$ \\
\hline & 2 & 1,02 & 3,51 & يتابع تنفيذ الأنشطة الصفية و اللاصفية. & $\begin{array}{l}18 \\
14\end{array}$ \\
\hline 3 & & 0,94 & 3,51 & متوسطة توظيف مركز مصنادر التعلم & $\begin{array}{l}15 \\
16\end{array}$ \\
\hline 4 & & 0,91 & 3,44 & يقوم بزيار ات صفية للمعلمين & \\
\hline
\end{tabular}




\begin{tabular}{|c|c|c|c|}
\hline & & & متو سطة \\
\hline 5 & 1,11 & 3,44 & يتابع تنفيذ الزيار ات المتبادلة بين المعلمين \\
\hline \multirow[t]{2}{*}{6} & 1,19 & 3,23 & متعقد الاجتماعات لمناقثة المستجدات \\
\hline & 0,57 & 3,44 & الارجة الكلية \\
\hline
\end{tabular}

يتضح من الجدول (8) أن تقديرات أفر اد عينة الدراسة لدور المشرف التربوي في تطوير الأداء

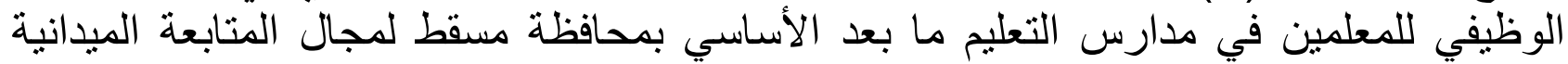

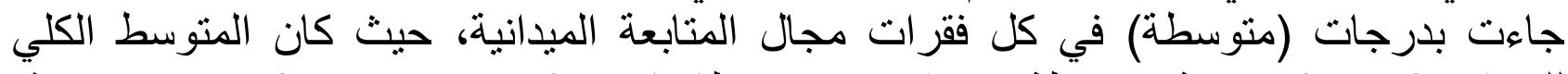

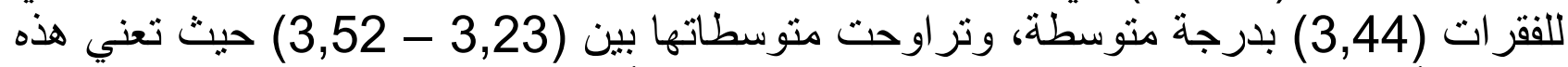

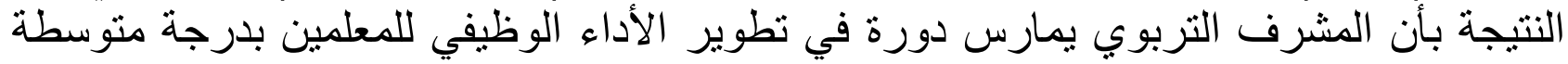

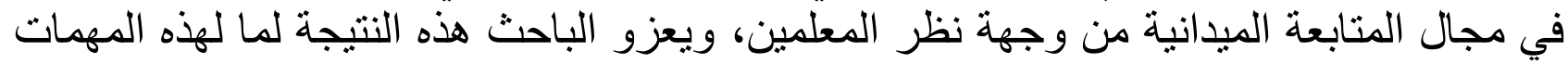

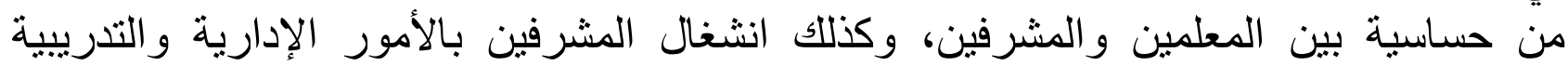

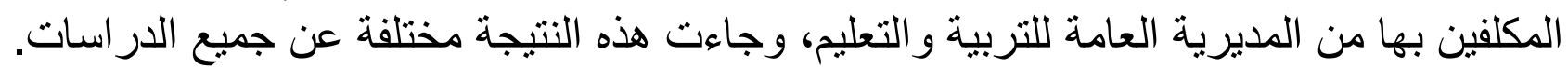
السؤال الثاني: - (الثي:

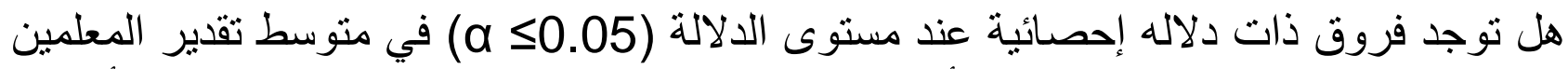

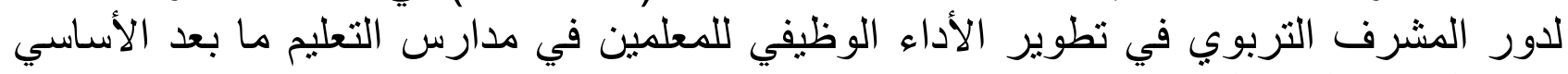

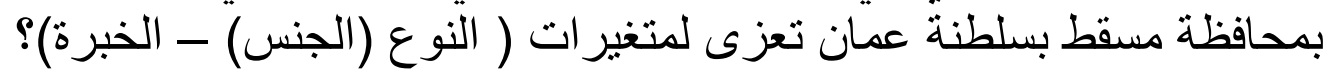

\section{1- 1 متغير النوع (الجنس)}

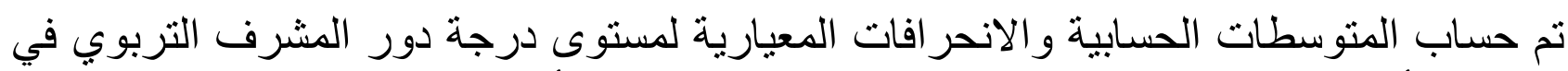

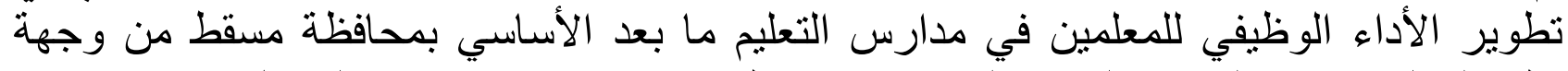

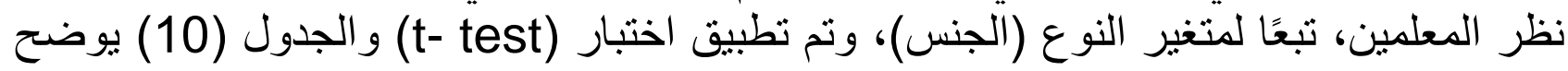
ذلك.

جدول (10) المتوسطات الحسابية والانحر افات المعيارية لدور المشرف التربوي في تطوير

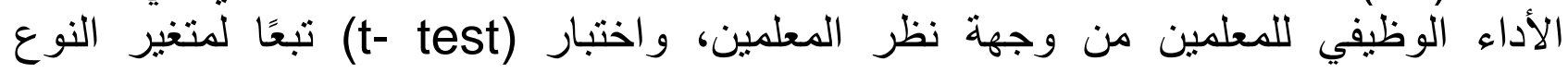
(الجنس). (اء ) (ال)

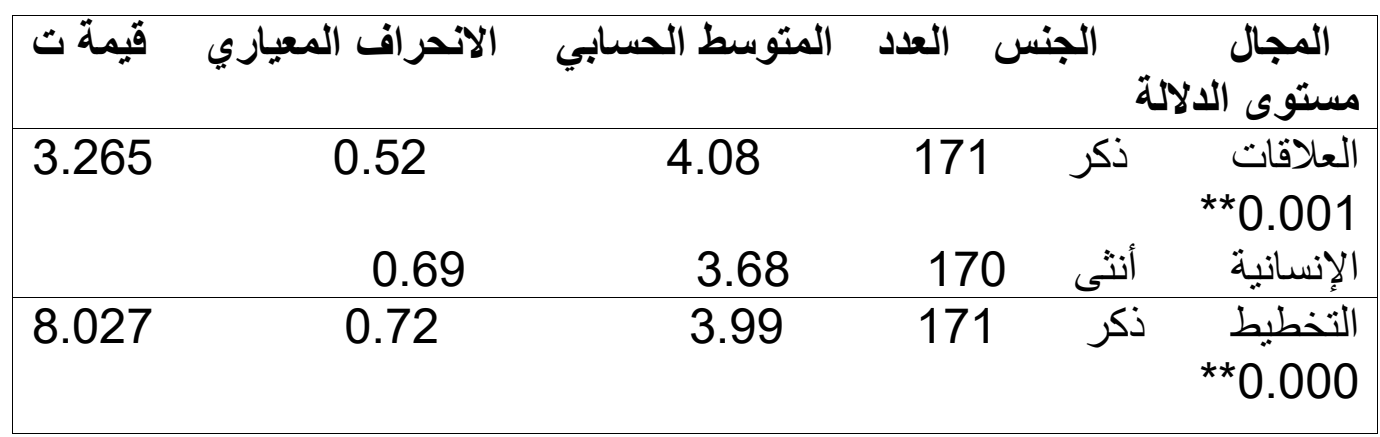




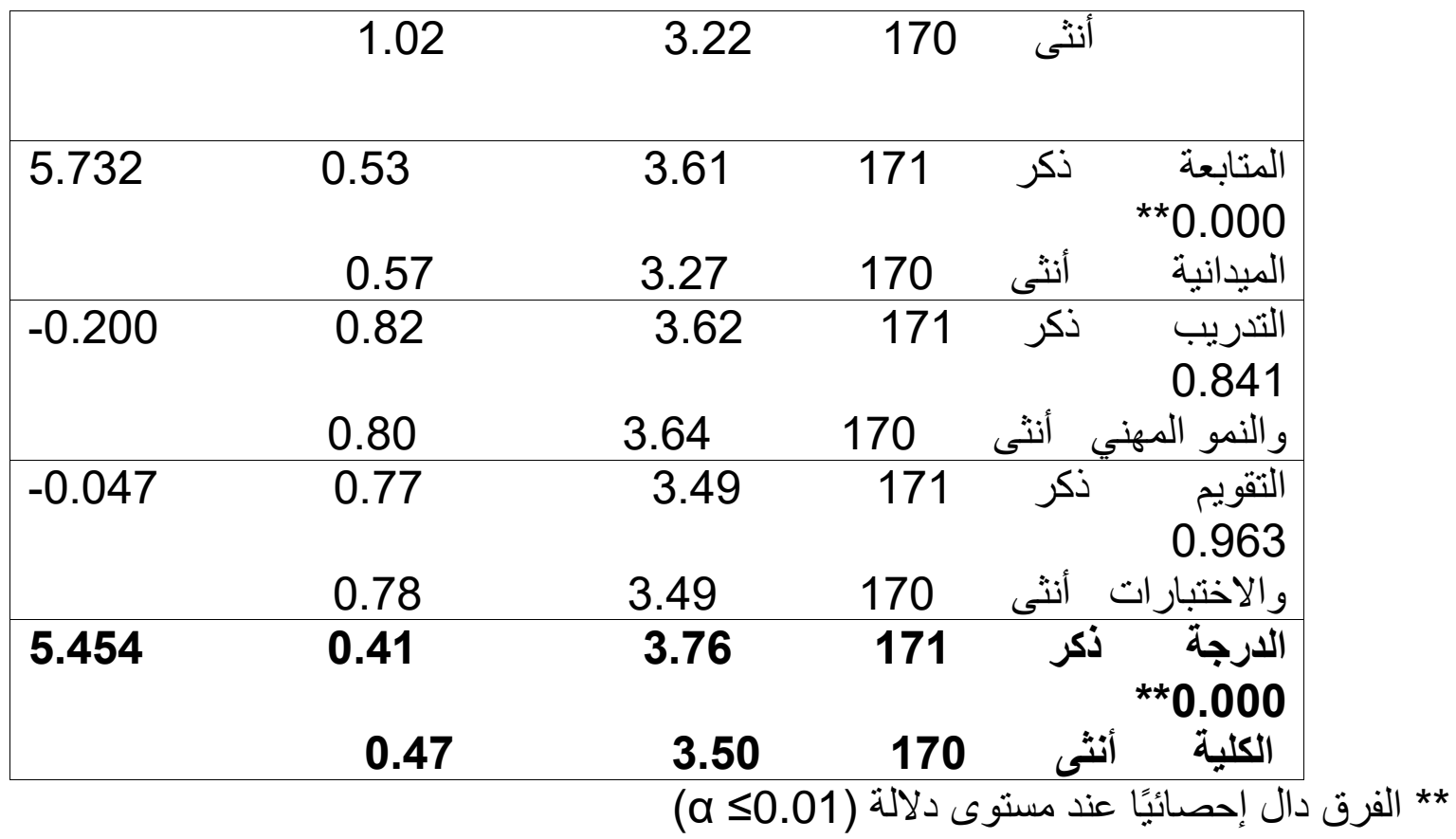

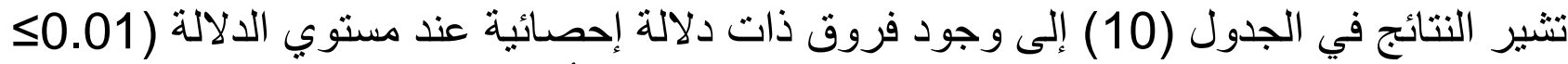

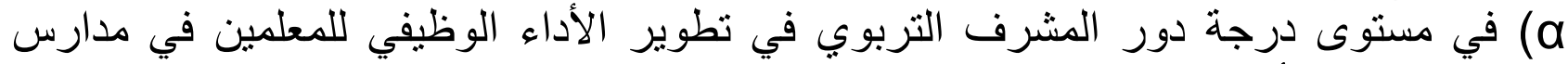

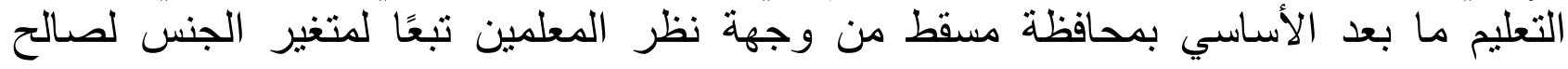
الذكور، وذللك استنادا إلّى قيمة (ت) بلى إذ بلغت قيمتها

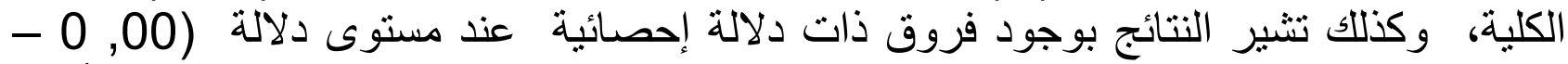

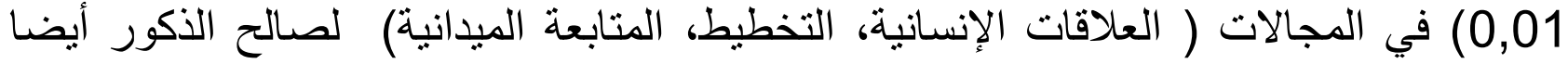
بدليل ارتفاع المنوسطات الحسابية.

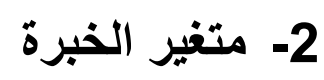

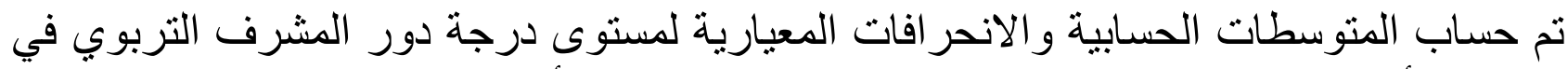

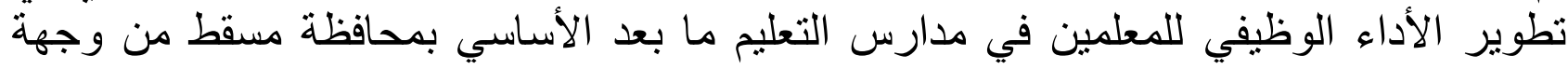

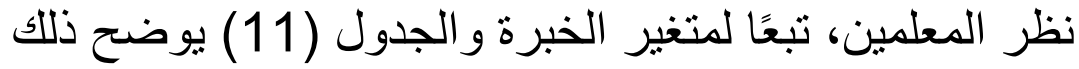

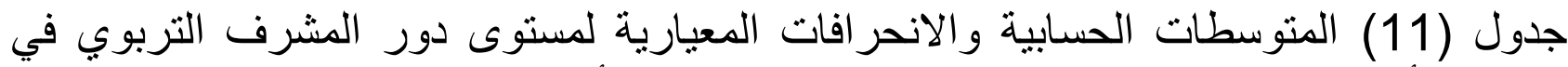

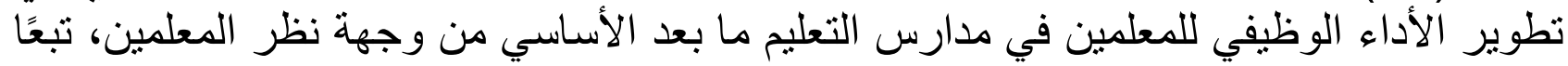
لمتغير الخبرة.

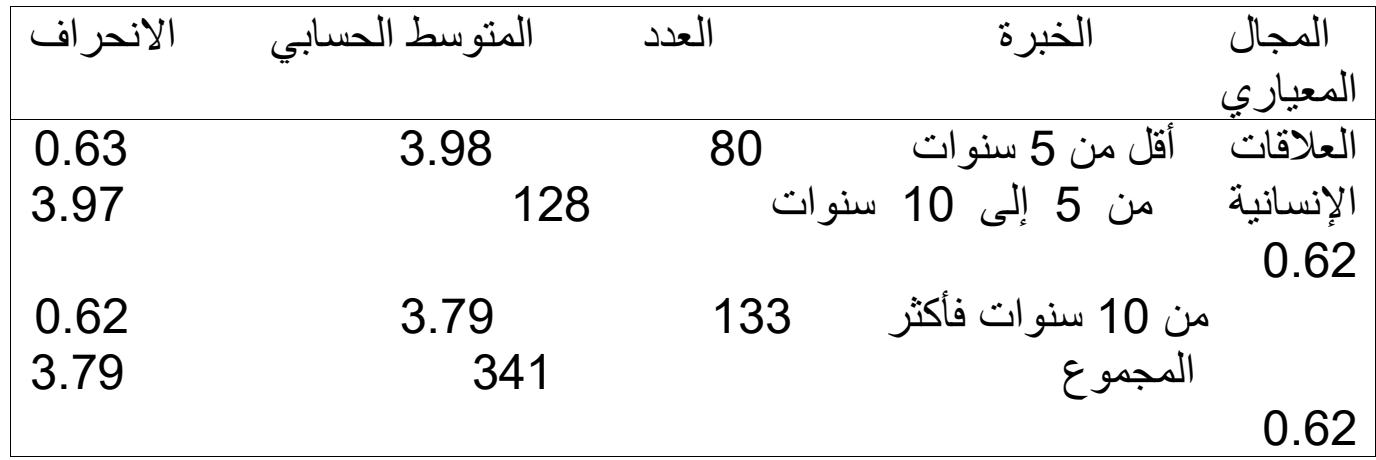




\begin{tabular}{|c|c|c|c|}
\hline 3.62 & 80 & أقل من 5 سنوات & التخطبط \\
\hline 3.60 & 128 & من 5 إلى 10 سنوات & 0.96 \\
\hline 3.60 & 133 & أكثر من 10 سنوات & 0.91 \\
\hline 3.61 & 341 & المجموع & \\
\hline & & 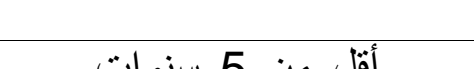 & $\begin{array}{l}0.96 \\
\text { المتابعة }\end{array}$ \\
\hline 3.47 & 80 & اقل من 5 سنوات & $\begin{array}{l}\text { المتابعة } 0.57 \\
0.57\end{array}$ \\
\hline 3.35 & 128 & من 5 إلى 10 سنوات & الميدانية \\
\hline 3.50 & 133 & أكثر من 10 سنوات & 0.02 \\
\hline 3.43 & 341 & المجموع & 0.52 \\
\hline & & & $\begin{array}{l}0.56 \\
\end{array}$ \\
\hline 3.74 & 80 & أقل من 5 سنوات & $\begin{array}{r}\text { التدريب } \\
0.72\end{array}$ \\
\hline 3.52 & 128 & من 5 إلى 10 سنوات & و النمو المهني \\
\hline 3.65 & 133 & أكثر من 10 سنوات & 001 \\
\hline 3.63 & 341 & المجموع & \\
\hline & & & 0.82 \\
\hline 3.60 & 80 & أقل من 5 سنوات & التقويم \\
\hline 3.38 & 128 & من 5 إلى 10 سنوات & $\begin{array}{r}\text { والاختبار ات } 0.75\end{array}$ \\
\hline 3.52 & 133 & أكثر من 10 سنوات & 0.84 \\
\hline 3.50 & 341 & المجموع & 0.77 \\
\hline 3.69 & 80 & أقلّ من 5 سنوات & الدارجة \\
\hline 3.55 & 128 & من5 إلى 10 سنوات & الكلية \\
\hline 3.65 & 133 & أكثر من 10 سنوات & 0.34 \\
\hline 3.63 & 341 & المجموع & 0.46 \\
\hline
\end{tabular}

يلاحظ في الجدول (11) بوجود فروق ظاهرية بين المتوسطات الحسابية لمستوى دور المشرف 
التربوي في تطوير الأداء الوظيفي للمعلمين في مدارس التعليم ما بعد الأساسي بمحافظة مسقط

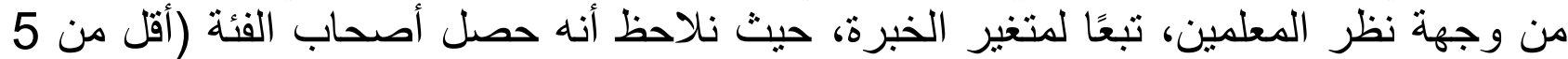

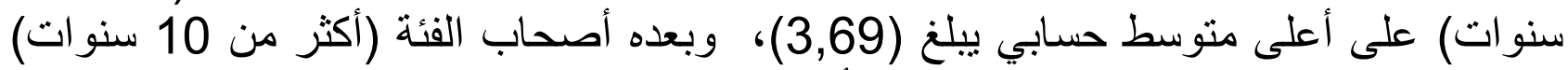

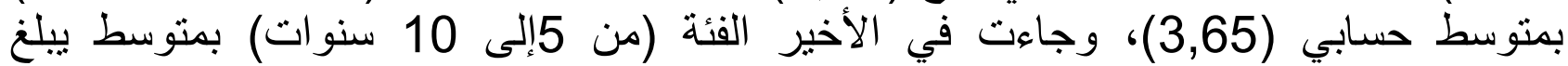
(3,55)، ولكي يحدد الباحث ما إذا كانت المتوسطات الحسابية ذات دلالة إحصائية، فقد فام بتطبيق تحليل التباين الأحادي ANOVA و الجدول (12) يوضح البح نتائج تحليل التباين. جدول (12) تحليل التباين الأحادي لإيجاد الفروق في تقدير ات المعلمين لدور المشرف التربوي بمدارس ما بعد الأساسي في محافظة مسقط. تبعًا لمتغير الخبرة الخبرة

\begin{tabular}{|c|c|c|c|c|c|}
\hline قيمة & متوسط & درجات & مجموع & مصدر & مستوى المجال \\
\hline ف & المربعات & الحرية & المربعات & التباين & الدلالة \\
\hline 0.002 & 0.001 & 2 & 0.00 & بين المجمو عات & العلاقات \\
\hline & 0.384 & $\begin{array}{c}339 \\
341\end{array}$ & $\begin{array}{l}130.52 \\
130.52\end{array}$ & الدجمو المجمو عات & الإنسانية \\
\hline 0.013 & 0.012 & 2 & 0.02 & بين المجمو عات & التخطبط \\
\hline & 0.931 & $\begin{array}{l}339 \\
341\end{array}$ & $\begin{array}{c}315.37 \\
315.39\end{array}$ & داخل المجموعات & 0.981 \\
\hline 2.550 & 0.832 & 2 & 1.66 & بين المجموعات & المتابعة \\
\hline & 0.326 & $\begin{array}{l}339 \\
341\end{array}$ & $\begin{array}{c}110.58 \\
112.24\end{array}$ & 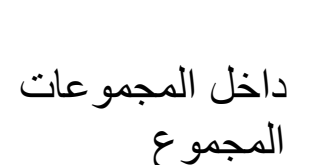 & $\begin{array}{l}0.081 \\
\text { الميدانية }\end{array}$ \\
\hline 2.090 & 1.362 & 2 & 2.71 & بين المجموعات & التدريب \\
\hline & 0.651 & $\begin{array}{c}339 \\
341\end{array}$ & $\begin{array}{r}220.55 \\
223.26\end{array}$ & داخل المجموعات & والنمو المهني \\
\hline 2.519 & 1.494 & 2 & 2.89 & بين المجموعات & التقويم \\
\hline & 0.593 & $\begin{array}{l}339 \\
341\end{array}$ & $\begin{array}{l}201.24 \\
204.23\end{array}$ & 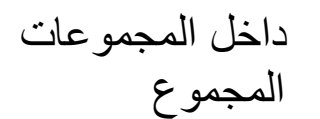 & و الاختبار ات \\
\hline 2.033 & 0.426 & 2 & 0.85 & بين المجموعات & الارجة \\
\hline & 0.211 & $\begin{array}{c}339 \\
341\end{array}$ & $\begin{array}{l}71.11 \\
71.96\end{array}$ & داخل المجموعات & الكلية \\
\hline
\end{tabular}

تشير النتائج في الجدول (12) بعدم وجود فروق ذات دوب دلالة إحصائية عند مستوي الدلالة

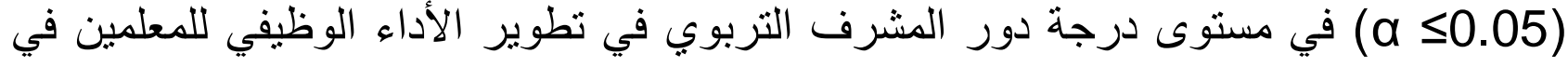


مدارس التعليم ما بعد الأساسي بمحافظة مسقط من وجهة نظر المعلمين تبعًا لمتغير الخبرة،

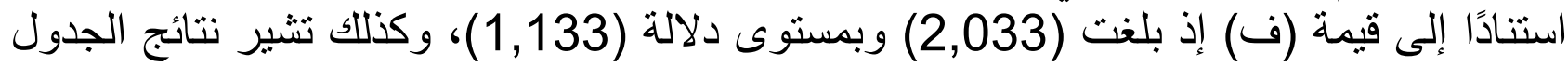
بعدم وجود فروق ذات دلالة إحصائية في جميع المجالات.

قائمة المراجع

الأخزمي، عصرية بنت ناصر بن علي.(2010). الددرسة كوحدة للتنمية المهنية، دورية الإنماء المهني

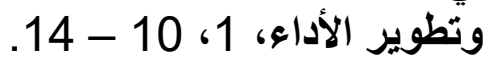

الإسحاقية، رقية سليمان. (2017). ممارسة المشرف التربوي للاروس التطبيقية كأسلوب إثرافي وعلاقته

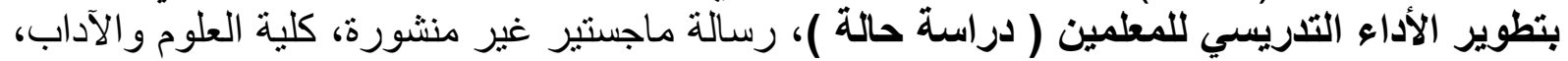
جامعة نزوى، سلطنة عُمان.

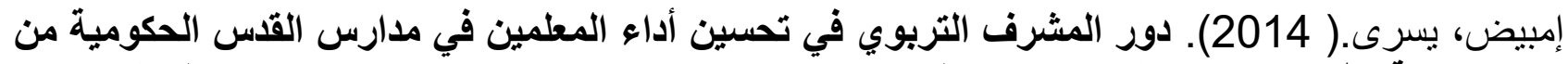
وجهة نظر المعلمين والمديرين، رسالة ماجستير غير منشورة، جامعة بيرزيت، بيرين فيريت، فلسطين.

الحجري، ناصر سلطان. (2014)، أنموذج مقترح لتحسين الممارسات الإشراقية لاى المشرفين التربويين بوزارة التربية والتعليم في سلطنة عُمان، رسالة ماجستير غير منشورة، كلية العلوم والآداب، جامعة التئة نزوى، سلطنة عمان. الحداد، مها منير.(2017). تطوير أداء مدير المدرسة بمدارس وكالة الغوث في محافظة فئة غزة كمشرف مقيم

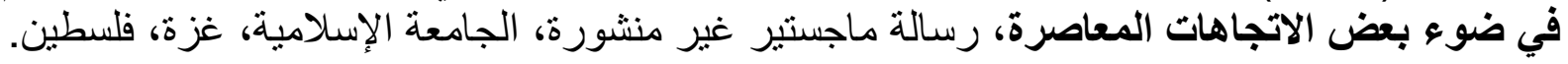
دفع الله، عمار محمح و حامد، صباح الحاج. (2018)، واقع الإتشراف التربوي ودوره في تطوير الكفايات

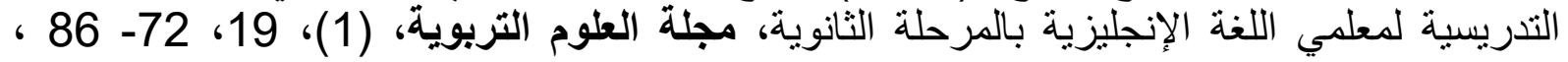

$$
\text { جامعة الملك سعود، الرياض. }
$$

دو اني، كمال.(2014). الإثراف التربوي مفاهيم وآفاق، دار الراية للنشر و التوزيع، عمان: الأردن.

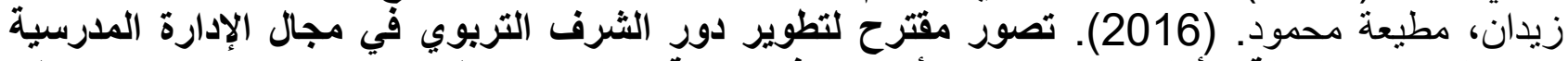

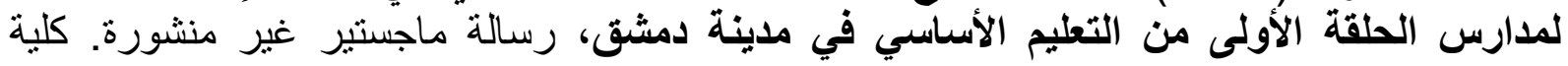

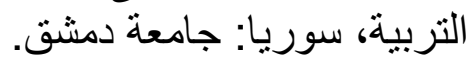

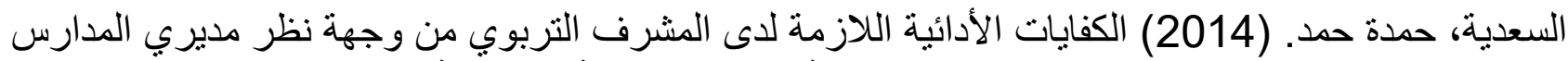

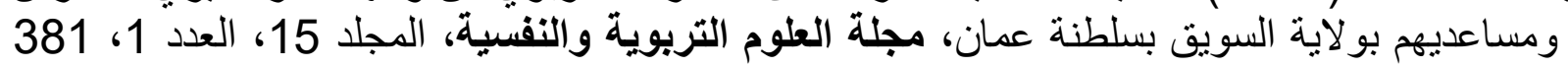

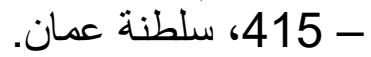

شديفات، باسل.(2014). دور المشرفين التربويين في تطوير الأداء المهني لمعلمي الدراسات الاجتماعية في في

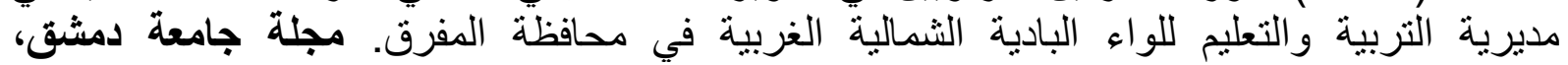
.339-299:(2)30

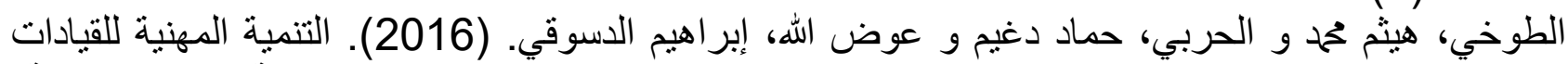

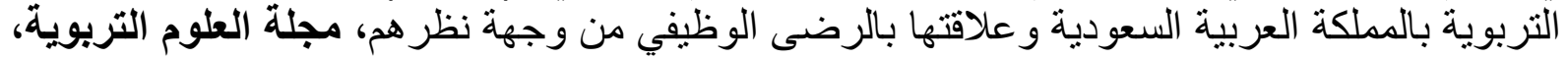
كلية الدراسات العليا للتربية، جامعة القاهرة، 3 (3)، 406 - 441. عطبر، ربيع شفيق. (2017). دور الإشراف التربوي في التنمية المهنية لمعلمي المرحلة الثنانوية بمدارس محافظة طولكرم الحكومية، مجلة العلوم التربوية والنفسية (البحرين)، 18 (1)، 621- 655. العلوية، منى. (2014). تصور مقترح لتفعيل الإشراف التربوي بمدارس التعليم ما بعد الأساسي بمدارس 
محافظة مسقط في ضوء نموذج الإشراف المتنوع. رسالة ماجستير غير منشورة، كلية التربية، جامعة

علي، ححم السيد. (2010). موسوعة المصطلحات التريوية. عمان: دار الميسرة للنشر والتوزيع. العمايرة. ححم حسن.(2014). الاحتياجات التدريبية لمديري المدارس الأساسية ومديراتها ومساعديهم في مدارس وكالة الغوث الدولية في الأردن من وجهة نظرهم، مجلة اتحاد الجامعات العربية للتربية وعلم النفس، سوريا، 12 (4)، 11 14 40.

العويسي، رجب علي.(2011). أهمية العلاقات الإنسانية للمشرف التربوي وأثزها في تعزيز الممارسات الإيجابية مع المعلمين. مجلة رسالة التربية، (32)، 52011)

الغافرية، وضحا علي.(2014). دور المشرفين الإداريين في التنمية المهنية لمديري مدارس التعليم

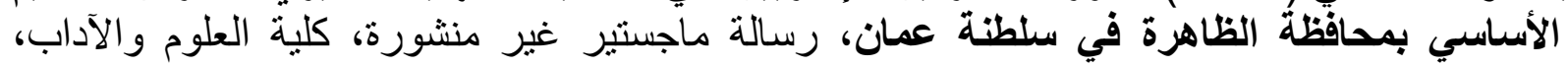
جامعة نزوي، سلطنة عُمان.

الغزو، أثرف مطلق. (2019). دور مدير المدرسة كمشرف تربوب مقيم في المدارس الثانوية في محافظة

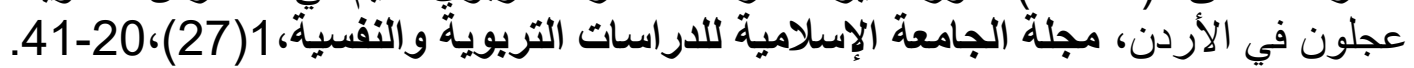

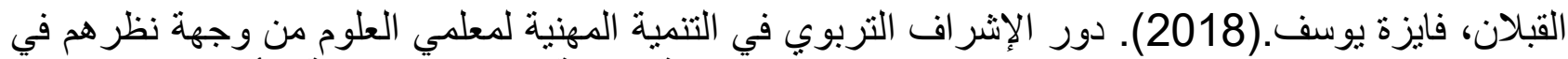

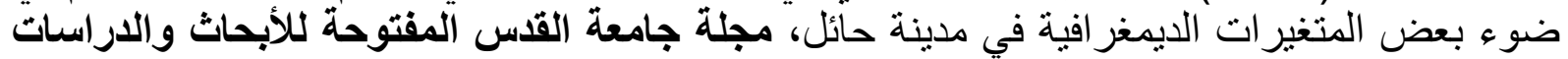

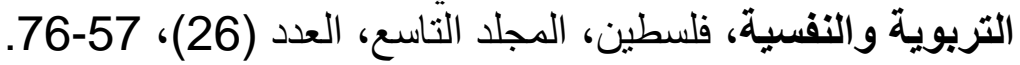

قطاف، حياة (2017) دور المشرف التربوي في تحسين الأداء التدريسي للمعلم في المرحلة الابتدائية دراسة المانة ميدانية لبعض المقاطعات بولاية المسيلة، رسالة ماجستير غير فير منشورة، كلية العلوم الإنسانية و الاجتماعية، جامعة محمد بوضياف المسيلة، الجز ائر. الكسباني، ححم علي السيد. (2012). البحث التربوي بين النظرية والتطبيق. القاهرة: دار الفكر العربي. الكلباني، يونس حمدان.(2016). مدى ممارسة المشرفين التربويين لبعض أنماط الإشراف التربوي في مدارس التعليم الأساسي بمحافظة الوسطى بسلطنة عمان، رسالة ماجستير غير منشورة التئ، كلية العلوم و الآداب، جامعة نزوى، سلطنة عُمان.

وزارة التربية والتعليم(2015) دليل الإشراف التربوي ، غير منشور، مسقط ، مطبوعات وزارة التربية و التعليم.

وزارة التربية والتعليم.(2013). الإثراف التربوي علاقة إنسانية وطموح تربوي ( التطوير التربوي)، مسقط، مطبو عات وزارة التربية و التعليم.

\section{ARABIC REFERENCES IN ROMAN ALPHABET}

Al'akhzamiu, Easriat Bnt Nasir Bin Ely.(2010). Almadrasat Kawahdat Liltanmiat Almihniati, Dawriat Al'inma' Almahni Watatwir Al'ada', 1, 10 - 14.

Al'iishaqiat, Raqiat Saliman. (2017). Mumarasat Almusharif Altarbuii Lildurus Altatbiqiat Ka'uslub 'lishrafiin Waealaqatih Bitatwir Al'ada' Altadrisii Lilmuelimin ( Dirasatan Halatan ), Risalat Majstayr Ghyr Manshuratin, Kuliyat Aleulum Waladabi, Jamieatan Nazwaa, Saltanat Euman.

'limbid, Yisraa.( 2014). Dawr Almushrif Altarbawii Fi Tahsin 'Ada' Almuealimin Fi Madaris Alquds Alhukumiat Min Wijhat Nazar Almuealimin Walmadirina, Risalat Majstayr Ghyr Manshurat, Jamieat Birzit, Biarzit, 
Filastin.

Alhijri, Nasir Sultan. (2014), 'Anmudhaj Muqtarah Litahsin Almumarasat Al'iishraqiat Ladaa Almushrifin Altarbuiiyn Biwizarat Altarbiat Waltaelim Fi Saltanat Euman, Risalat Majstayr Ghyr Manshuratin, Kuliyat Aleulum Waladabi, Jamieat Nazwaa, Saltanat Eaman.

Alhadadi, Maha Manyr.(2017). Tatwir 'Ada' Mudir Almadrasat Bimadaris Wikalat Alghawth Fi Muhafazat Ghazat Kamashrif Muqim Fi Daw' Bed Alaitijahat Almueasirati, Risalat Majsatayr Ghyr Minshurat, Aljamieat Al'iislamiati, Ghazat, Filastin.

Dafe Allah, Eammar Muhamad W Hamid, Sabah Alhaji. (2018), Waqie Al'iishraf Altarbuii Wadawrih Fi Tatwir Alkiffayat Altadrisiat Limuelimi Allughat Al'iinjliziat Bialmarhalat Alththanuiat, Majalat Aleulum Altarbawiati, (1), 19, 72- 86 ,

Jamieat Almalik Sueud, Alriyad. Dawani, Kmal.(2014). Al'iishraf Altarbuiu Mafahim Wafaqi, Dar Alrrayat Lilnashr Waltawziei, Eimana: Al'urdunn.

Zaydan, Matieat Mahmud. (2016). Tasawur Muqtarah Litatwir Dawr Alsharaf Altarbwii Fi Majal Al'iidarat Almadrasiat Limadaris Alhalqat Al'uwlaa Min Altaelim Al'asasii Fi Madinat Dimashqa, Risalat Majstayr Ghyr Manshuratin. Kuliyat Altarbiati, Surya: Jamieat Dimashq.

Alsiediatu, Hamdat Hmd. (2014) Alkifayat Al'adayiyat Alllazimat Ladaa Almashrif Altarbuii Min Wijhat Nazar Mudiri Almadaris Wamusaeidihim Biwilayat Alsawiq Bisiltanat Eaman, Majalat Aleulum Altarbawiat Walnafsiati, Almujalid 15, Aleadad 1, 381 - 415,

Saltanatan Eamaan. Shadifat, Basl.(2014). Dawr Almushrifin Altarbuiiyn Fi Tatwir Al'ada' Almahnii Limuelami Aldirasat Alaijtimaeiat Fi Mudiriat Altarbiat Waltaelim Lilwaa' Albadiat Alshamaliat Algharbiat Fi Muhafazat Almafraq. Majalat Jamieat Dimashq, 30(2):339-299.

Altuwkhi, Haytham Muhamad W Alharibi, Hammad Daghim W Eiwad Allih, 'librahim Aldisuqi. (2016). Altanmiat Almihniat Lilqiadat Altarbawiat Bialmamlakat Alearabiat Alsaeudiat Waealaqatiha Bialradaa Alwazifii Min Wijhat Nazarihim, Majalat Aleulum Altarbawiati, Kuliyat Aldirasat Aleulya Liltarbiati, Jamieat Alqahirat, 3 (3), 406 - 441.

Eatir, Rbye Shafiq. (2017). Dawr Al'iishraf Altarbawii Fi Altanmiat Almihniat Limuelimi Almarhalat Alththanawiat Bimadaris Muhafazat Tulkarm Alhukumiati, Majalat Aleulum Altarbawiat Walnafsiata(Alibahrayn), 18 (1), 621 - 655.

aleilawiat, manaa. (2014). tasawur muqtarah litafeil al'iishraf altarbuii bimadaris altaelim ma baed al'asasii bimadaris muhafazat masqat fi daw' namudhaj al'iishraf almutanawe. risalat majstayr ghyr manshurati, kuliyat altarbiat, jamieat nazwaa, saltanat euman.

eali, muhamad alsayd. (2010). mawsueat almustalahat altarbawiat. eamana: dar almaysrat lilnashr waltawzie.

alemayra. muhamad hsn.(2014). alaihtiajat altadribiat limudiri almadaris al'asasiat wamudiratiha wamusaeidihim fi madaris wikalat alghawth alduwaliat fi al'urduni min wijhat nazarihim, majalat aitihad aljamieat alearabiat liltarbiat waealam alnafsi, surya, 12 (4), 11- 40.

aleuysi, rajab euly.(2011). 'ahamiyat alealaqat al'iinsaniat lilmushrif altarbawii wa'athariha fi taeziz almumarasat al'iijabiat mae almuelimin. majalat risalat altarbiati, (32), 52-70.

alghafiriat, wadaha ealy.(2014). dawr almusharifin al'iidariiyn fi altanmiat almihniat limudiri madaris altaelim al'asasii bimuhafazat alzzahirat fi saltanat eumaan, risalat majsatayr ghyr manshuratin, kuliyat aleulum waladabi, jamieatan nazwi, saltanat euman.

alghazu, 'ashraf matluq. (2019). dawr mudir almadrasat kamashrif tarbwi muqim fi almadaris alththanawiat fi muhafazat eijlawn fi al'urduni, majalat aljamieat al'iislamiat lildirasat altarbawiat walnafsit,1(27),20-41.

alqablan, fayzt yusf.(2018). dawr al'iishraf altarbawii fi altanmiat almihniat limuelimi aleulum min wijhat nazarihim fi daw' bed almutaghayirat aldiymighrafiat fi madinat hayili, majalat jamieat alquds almaftuhat lil'abhath waldirasat altarbawiat walnafsiati, filastin, almujalid altaasie, aleadad (26), 76-57.

qataf, haya (2017) dawr almusharif altarbawiu fi tahsin al'ada' altadrisii lilmuelam fi almarhalat alaibtidayiyat dirasat maydaniat libaed almuqataeat biwilayat almasilati, risalat majsatayr ghyr manshurati, kuliyat aleulum al'iinsaniat walaijtimaeiati, jamieatan muhamad bawdiaf almasaylata, aljazayir.

alkusbani, muhamad eali alsayd. (2012). albahth altarbawy bayn alnazaryat waltatbiqa. alqahirat: dar alfikr alearabi. alkulbani, yunis hmdan.(2016). madaa mumarasat almushrifin altarbuiiyn libaed 
'anmat al'iishraf altarbawii fi madaris altaelim al'asasii bimuhafazat alwustaa bisiltanat eumaan, risalat majstayr ghyr manshuratin, kuliyat aleulum waladabi, jamieat nazwaa, saltanat euman.

wizarat altarbiat waltaelim(2015) dalil al'iishraf altarbuii , ghyr munshuirin, masqat , matbueat wizarat altarbiat waltaelim.

wizarat altarbiat waltaelim.(2013). al'iishraf altarbawiu ealaqat 'iinsaniatan watumuh turbwy ( altatwir alturbuaya), masqati, matbueat wizarat altarbiat waltaelim.

\section{REFERENCES}

Abubakr, A. M., Shagari, S. L., Aliyu, A., Ahmed, I., Karamba, K. I., Maji, I. K., ... \& Ya'u, M. S. (2015). THE ROLE OF EDUCATIONAL SUPERVISORS TOWARDS IMPROVING TEACHERS PERFORMANCE. Journal of Chemical and Pharmaceutical Sciences, 8(2), 401-406.

Al-Munnir, AbuBak. (2018). The Role of Educational Supervisors Towards Improving Teachers Performance. BauchiState University . Available online :

https://www.researchgate.net/publication/323114130.Accessed,12th February,2019.

Ajur, I., IsI, W., Ololubei, N. P., \& Majorii, N. B. (2014). School Inspection Impact on Teachers' Produ Teacher Education. International Journal of Scientific Research in Education, 91. Available on: https://www.researchgate.net/publication/283081835.Accessed 25th February,2019.

Bidzakin, V. K. (2018). ENHANCING TEACHER SUPERVISION IN THE KUMBUNGU TOWNSHIP OF THE NORTHERN REGION OF GHANA (Doctoral dissertation).

Chen, C. W. Y., \& Cheng, Y. S. (2013). The Supervisory Process of EFL Teachers: A Case Study. TESLEJ, 17(1), n1. Taiwan.

Christian, O., Manfred, P. \& Reinders, D. (2010). The Sinus Project as an Example for Reform as Teacher Professional Development. International Journal of Science Education, Vol. 23 (3), p 303-327.

Costellow, T. D. (2011). The Preferred Principal: Leadership Traits, Behaviors, and Gender Characteristics School Teachers Desire in a Building Leader. unpublished Ph.D. thesis. University Bowling Green , Kentucky.

Hamzah, M. I. M., Wei, Y., Ahmad, J., Hamid, A. H. A., \& Mansor, A. N. (2013). Supervision Practices and Teachers' Satisfaction in Public Secondary Schools: Malaysia and China. International Education Studies, 6(8), 92-97.

Hoojqan, A., Gharamani, J. \& Safari, S. (2015). The effect of educational supervision on improving teachers' performances in Guidance Schools of Marand. Indian Journal of Fundamental and Applied Life Sciences, 5(2), 1731-1735.

Kotirde, I. Y., \& Yunos, J. B. M. (2015). The Processes of Supervisions in Secondary Schools Educational System in Nigeria. Procedia-Social and Behavioral Sciences, 204, 259-264.

LOPEZ, M. C. A. (2016). Classroom Supervisory Practices and Their Relationship to Teacher Effectiveness As Perceived By Secondary Teachers. SMCC Higher Education Research Journal, 2(1), 1-1.

Määttä, K., Uusiautti, S., \& Alila, S. (2016). The Principles and Practices of Supervision That Supports the Development of Inclusive Teacherhood. Journal of Education and Learning, 5(3) 297-309.

Tesfaw, T. A., \& Hofman, R. H. (2014). Relationship between instructional supervision and professional development. International Education Journal: Comparative Perspectives, 13(1), 82-99.

Yasin, M.; Mustamin, D. and Tahir, L. M. (2013). Principal Competencies and the Achievement of National Education Standard in Indonesia. International Journal of Humanities and Social Science , 2 (8) , PP $31-36$. 